Aus der Klinik für Zahnärztliche Prothetik, Propädeutik und Werkstoffkunde (Direktor: Prof. Dr. M. Kern)

Universitätsklinikum Schleswig-Holstein, Campus Kiel an der Christian-Albrechts-Universität zu Kiel

\title{
RETENTIVE FORCES AND FATIGUE RESISTANCE OF THERM OPLASTIC RESIN CLASPS
}

\author{
Inauguraldissertation \\ zur \\ Erlangung der Würde eines Doktors der Zahnheilkunde \\ der Medizinischen Fakultät \\ der Christian-Albrechts-Universität zu Kiel
}

vorgelegt von

FAHED TANNOUS

aus Syrien

Kiel 2013 
1. Berichterstatter:

(Prof. Dr. Matthias Kern, Klinik für Zahnärztliche Prothetik, Propädeutik und Werkstoffkunde)

2. Berichterstatter:

(Prof. Dr. Helge Fischer-Brandies, Klinik für Kieferorthopädie)

Tag der mündlichen Prüfung: $\quad$ 25.06.2013

Zum Druck genehmigt, Kiel, den 25.06.2013

gez.:

(Prof. Dr. Hans-Jürgen Wenz)

(Prof. Dr. Johann Roider) 


\section{Index}

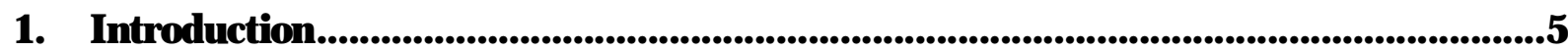

1.1. Need for partial removable dental prostheses (PRDPs) ............................................5

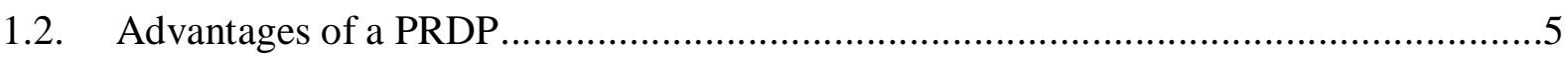

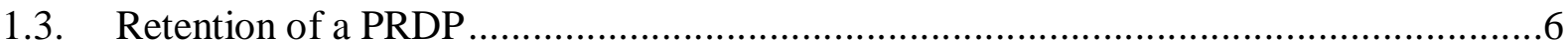

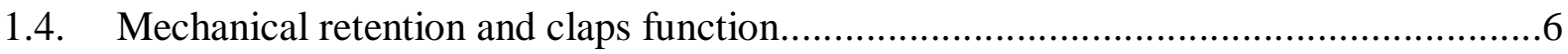

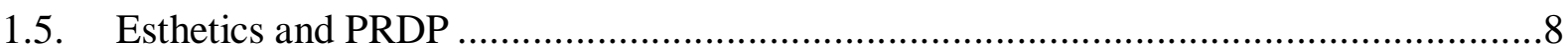

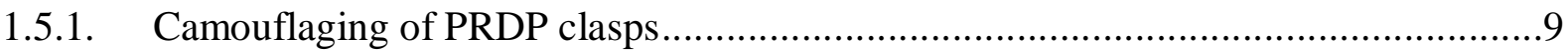

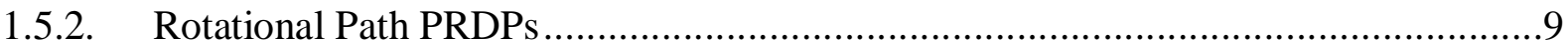

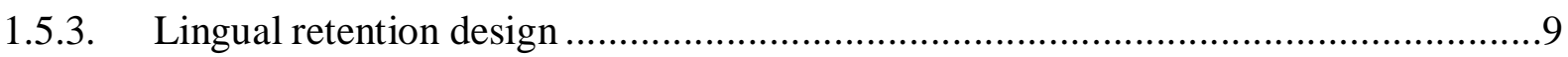

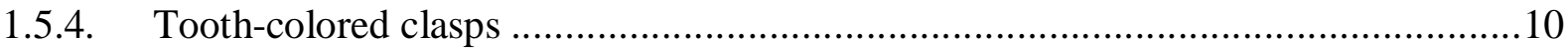

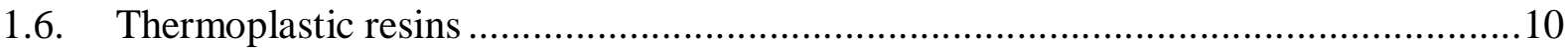

1.6.1. Polyoxymethylene (POM) .................................................................... 10

1.6.2. Polyetheretherketon (PEEK) and Polyetherketonketon (PEKK) ...........................10

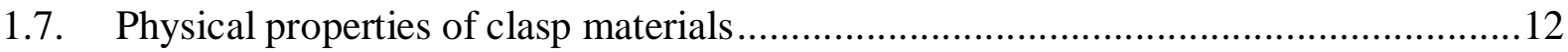

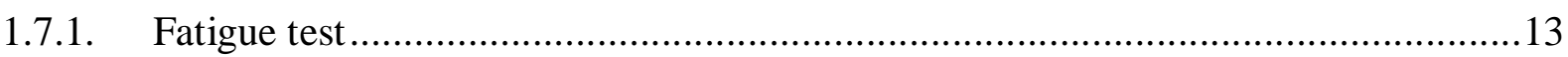

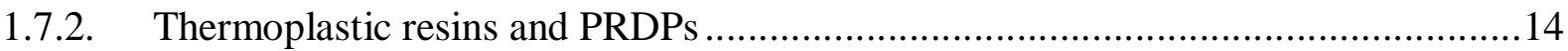

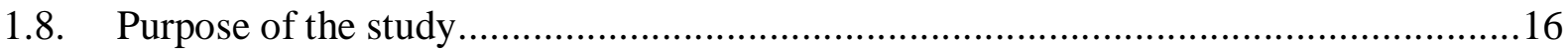

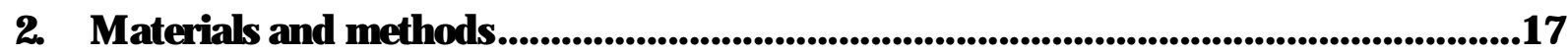

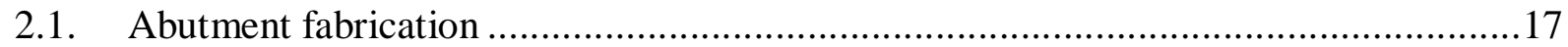

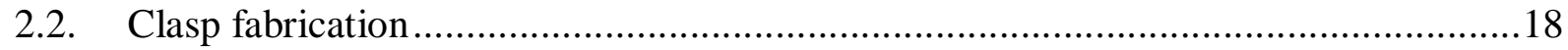

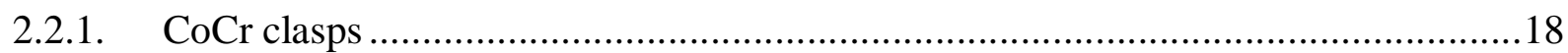




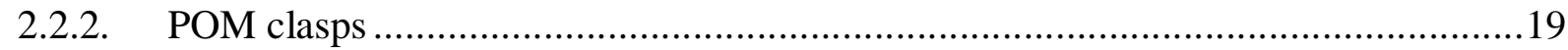

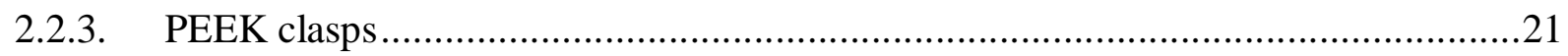

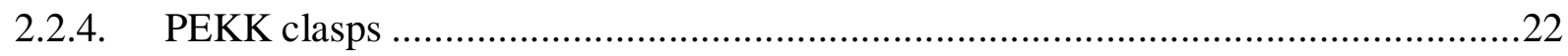

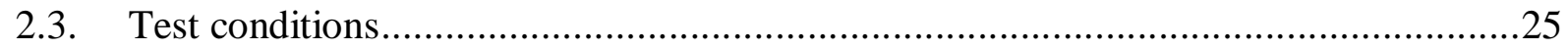

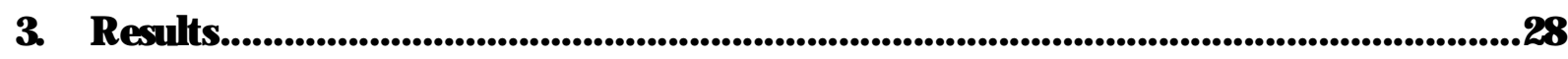

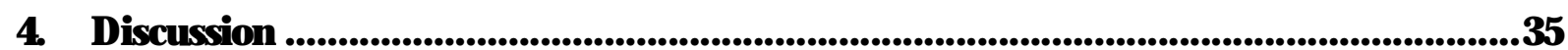

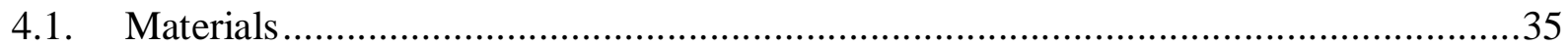

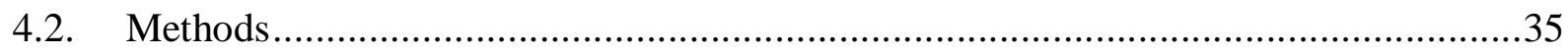

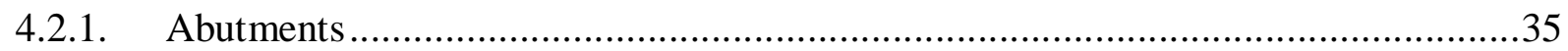

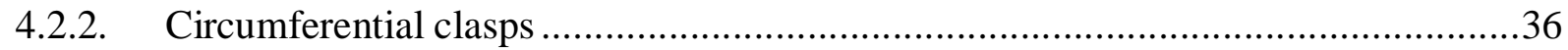

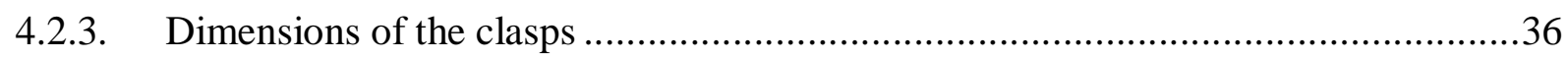

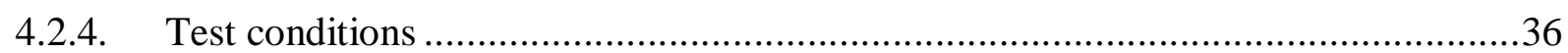

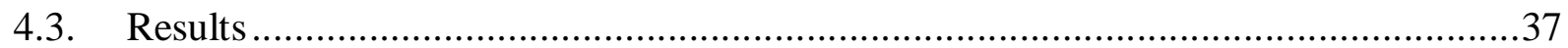

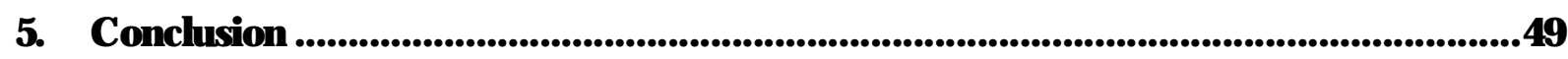

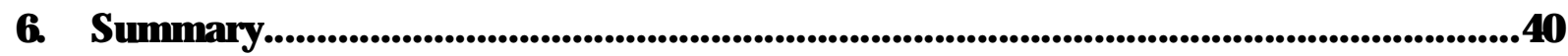

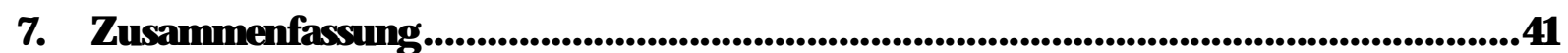

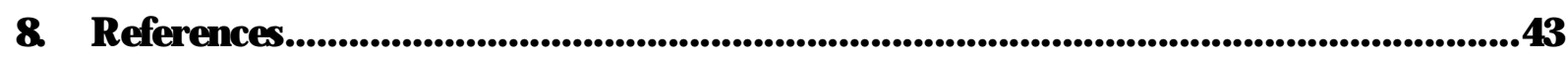

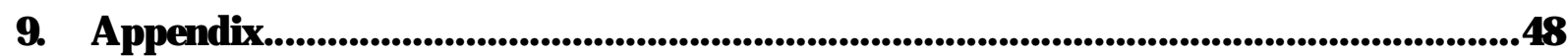


List of abbreviations:

CoCr: Cobalt choromium

PAEK: Polyaryletherketone

PEEK: Polyetheretherketon

PEKK: Polyetherketonketon

PFDP: Partial fixed dental prosthesis

PMMA: Polymethylmethacrylate

POM: Polyoxymethylene

PRDP: Partial removable dental prosthesis 


\section{Introduction}

\subsection{Need for partial removable dental prostheses (PRDPs)}

There is a steady trend towards an increase in the global population that is over 65 years old [34]. Over the past 50 years, tremendous emphasis has been placed on preventive dentistry and improving attitudes about the value of retaining natural teeth. The results of these efforts have been a significant improvement in oral health, a steady decline in the prevalence of natural tooth loss, and a reduction in the percentage of edentulous people [31, 45]. Consequently, the need for restoration of partially edentulous conditions will also be increasing [15].

For the elderly, PRDPs are one of the main types of restoration for missing teeth [69]. The replacement of missing teeth with a PRDP is linked to socio-economic status, demographics, education attainment levels and income. Patients with lower educational and socio-economic levels, or those living in rural areas, are more likely to choose an PRDP over a fixed modality [69].

\subsection{Advantages of a PRDP}

1. A PRDP can replace lost supporting tissues in addition to missing teeth. Normal contour, appearance, and facial support may be restored with the acrylic resin denture base material where bone and alveolar tissue have been lost.

2. A PRDP can use soft tissue areas of the mouth for support in addition to using the teeth, so a PRDP may function successfully when the teeth alone cannot support a partial fixed dental prosthesis (PFDP).

3. A PRDP may help the patient maintain a more acceptable level of oral hygiene. Use of a PRDP enables the patient to clean both the prosthesis and the remaining natural teeth, since the prosthesis can be removed.

4. A PRDP may be designed to splint and stabilize weakened abutment teeth and prevent the loosening, drifting, or extrusion of retained teeth. The cost of cast restorations and 
the problem of unhygienic soldered splints may sometimes be avoided when a PRDP is used.

5. A PRDP may be designed to distribute the forces of mastication on to many support areas and to multiple abutment teeth to prevent overloading only two or three teeth [31].

\subsection{R etention of a PRDP}

Retention is the ability of a PRDP to resist dislodging forces during function and can be achieved by [12]:

1. Using mechanical means such as clasps which engage undercuts on the tooth surface.

2. Harnessing the patient's muscular control acting through the polished surface of the denture.

3. Using the inherent physical forces which arise from coverage of the mucosa by the denture.

\subsection{M echanical retention and claps function}

The clasp assembly is that part of a PRDP that acts as a direct retainer to prevent dislodgement by encompassing and contacting an abutment tooth. It is composed of a rest, a retentive arm, proximal plate, and bracing components (Fig. 1) [31].

There are six factors that are required of a clasp assembly [31]:

1. Retention: Provides resistance to vertical dislodgement.

2. Stability: Provides resistance to horizontal forces.

3. Support: Provides resistance to vertical seating.

4. Reciprocation: Provides resistance to horizontal forces exerted on a tooth by an active retentive clasp. 
1. Encirclement: Engages the tooth greater than $180^{\circ}$ to prevent horizontal tooth movement from within the confines of a clasp assembly.

2. Passivity: Puts no active force on a tooth when a clasp is in place.

Whatever type of clasp is used a denture will be retained successfully only as long as the force required to flex the clasps over the maximum bulbosities of the teeth is greater than the force which is attempting to dislodge the denture [12].

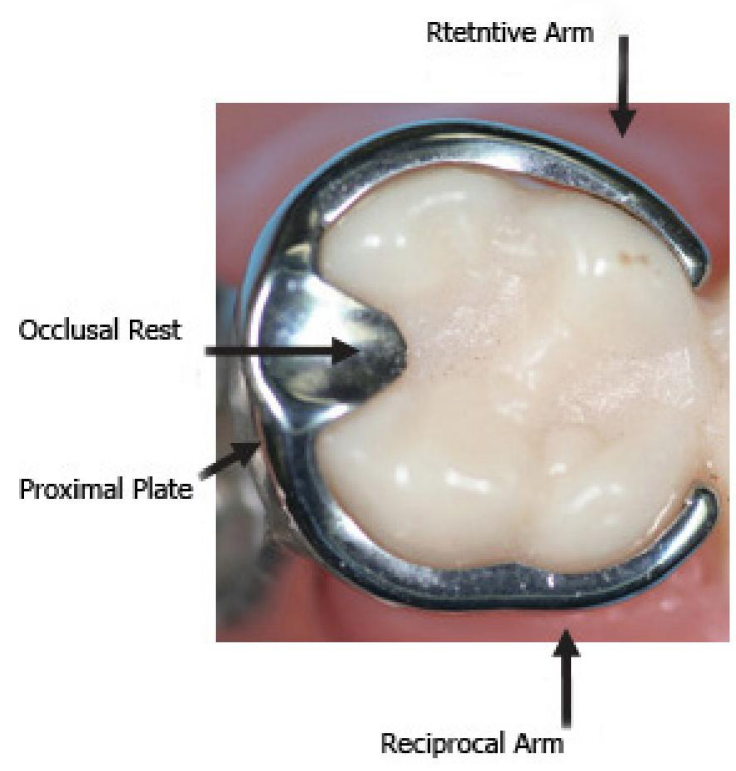

Fig.1. Circumferential clasp (left) and bar clasp (right) [31].

The retentive force is dictated by the condition of the abutment (shape, friction, and degree of undercut) and by the stiffness of the clasp arm (shapes and Young's modulus) [12, 51-52].

The flexibility of a clasp is dependent on its design [12]:

B Section: A round section clasp will flex equally in all directions, whereas a half round clasp will flex more readily in the horizontal than in the vertical plane.

B Length: The longer the clasp arm the more flexible it is. Thus an occlusally approaching clasp on a molar tooth will be more flexible than one on a premolar. 
B Thickness: Thickness has a profound effect on flexibility. If the thickness is reduced by half the flexibility is increased by a factor of eight.

B Curvature: A clasp which is curved in two planes can exhibit the so-called bucket handle' effect in which torsional movement of the clasp increases flexibility of the clasp arm.

B Alloy: Although all cast alloys used in PRDP construction possess flexibility, their flexibility is proportionate to their bulk [9].

The most common metal alloy used for this purpose is a cobalt-chromium alloy, but other alloys such as gold and titanium alloys can also be used [35, 49, 63, 65]. Round wrought wires flex in all directions and have been recommended for use as retentive clasp arms in all types of PRDPs, especially where periodontal support has been compromised, or the use of cast clasps has been deemed unsuitable. However, wrought wires have several potential disadvantages related to the failure as a result of poor adaptation, loss of adaption after a period of use and susceptibility [21, 64].

\subsection{Esthetics and PRDPs}

The emphasis on physical appearance in contemporary society has increased the demand for esthetic dental restorations. Although the success of implant dentistry has expanded the scope of esthetic fixed prostheses, there are still many patients who for health, anatomic, psychological, or financial reasons are not candidates for implants [14]. These patients have the option of receiving partial removable dental prostheses (PRDPs) to replace missing teeth. A major esthetical problem with PRDPs is the display of the clasp assemblies. 
Many methods have been used to overcome the esthetic problem such as:

\subsubsection{Camouflaging of PRDP clasps}

Etching the clasp arm and coating it with a layer of tooth-color resin, has been reported in the literature [44]. The difficulty with the use of acrylic resins or resin composite to veneer to PRDP metals lies in the differences between their abilities to flex and their coefficients of thermal expansion. Non-noble metals possess strength and resist significant flexure. However, resins are subjected to greater deformation from physical and thermal conditions. The resin composite matrix also tends to be brittle beyond its elastic limit. As a result, the abilities of the metals and resins to deform plastically are incompatible. Other concerns include the effect of the intraoral forces of mastication, the adjustability of veneered clasps, and the additional bulk of the clasp created by the addition of the veneering material. Excessive shortening and thinning of the clasp should be avoided to ensure rigidity and minimize the breakage potential of the clasp [56].

\subsubsection{Rotational path PRDPs}

The rotational path PRDP is a relatively uncomplicated method that eliminates the use of esthetically objectionable clasping in the anterior region of the mouth $[3-4,8,10,19,24,26$, 28-30, 38, 50, 57, 66-67]. It uses an anterior rigid portion of the framework and a conventional flexible posterior retentive clasp as the retentive components. The main advantage of this design is the minimal use of clasps. The esthetic result is enhanced, and the tendency toward plaque accumulation is reduced. However, both the clinical and laboratory procedures required for the rotational path PRDP are technique sensitive.

\subsubsection{Lingual retention design}

By eliminating the bracing arm and having its functions taken by paralleled guide planes and precise, positive rests, the retentive element, a lingual circumferential wire clasp arm, will provide the same amount of retentive force as if it were placed on the buccal surface and will not be visible [7, 10, 47]. 


\subsubsection{Tooth-color ed clasps}

Direct retainers fabricated in a tooth-colored material and made from thermoplastic resin have been used to improve the appearance of metal clasp assemblies and are promoted for superior esthetics $[1,20,61]$. However, little information on the long-term performance of such clasps regarding retention is available in the literature.

\subsection{Ther moplastic resins}

\subsubsection{Polyoxymethylene (POM )}

Polyoxymethylene (POM) also known as acetal resin, an injection-molded resin has been introduced as an alternative to conventional PMMA. POM is formed by the polymerization of formaldehyde. The homopolymer, polyoxymethylene is a chain of alternating methyl groups linked by an oxygen molecule [20] (Fig. 2). POM has a high degree of crystallinity and is known as one of the strongest and stiffest thermoplastic materials. In addition, it is a chemically very stable material, resistant to many solvents, disinfectants and to humidity, These properties, combined with the approved tissue compatibility, make POM a desirable material for medical application [16].

For more than two decades, POM has been used in dentistry all over the world as a substitute for acrylic resins and metals in many prosthetic applications. The most widely used appliances were the esthetic clasps of partial removable dental prostheses [1, 10, 58, 61], cast posts and cores [11, 42] and brackets [18].

\subsubsection{Polyetherether keton (PEEK) and Polyether ketonketon (PEK K)}

Polyetheretherketon (PEEK) and Polyetherketonketon (PEKK) are polymers from the group polyaryletherketone (PAEK) which is a relatively new family of high-temperature thermoplastic polymers, consisting of an aromatic backbone molecular chain, interconnected by ketone and ether functional groups [17, 36] (Fig. 2).

The chemical structure of polyaromatic ketones confers stability at high temperatures (exceeding $300{ }^{\circ} \mathrm{C}$ ), resistance to chemical and radiation damage, compatibility with many 
reinforcing agents (such as glass and carbon fibers), and greater strength (on a per mass basis) than many metals, making it highly attractive in industrial applications, such as aircraft and turbine blades [36].

Although neat (unfilled) polyaromatic polymers can exhibit an elastic modulus ranging from 3 to $4 \mathrm{GPa}$, the modulus can be tailored to closely match cortical bone (18 GPa) or titanium alloy (110 GPa) by preparing carbon-fiber-rein-forced (CFR) composites with varying fiber length and orientation [36].

In medicine PAEK has been demonstrated to be excellent substitute for titanium in orthopedic applications [36, 60], and it has been used in dentistry as provisional implant abutment [59].

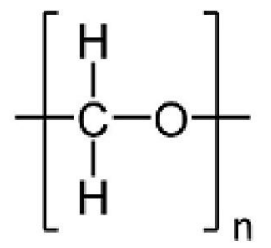

$$
\text { Poly - Oxy - Methylene (POM) }
$$
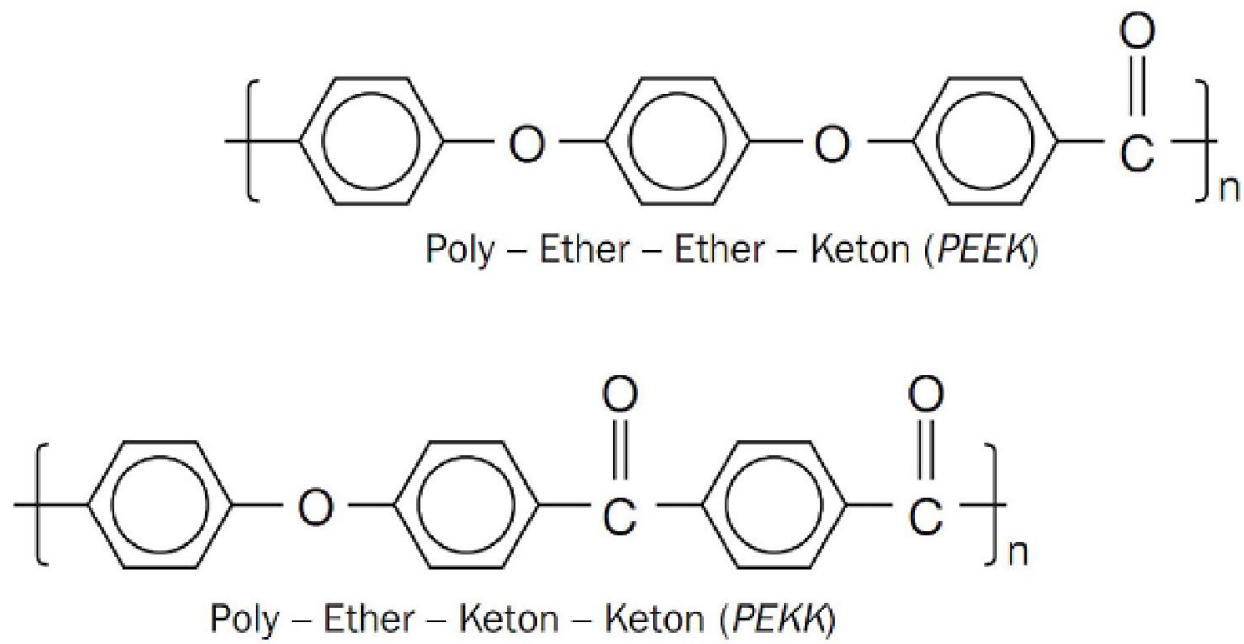

Fig. 2. Chemical structure of POM, PEEK and PEKK. 


\subsection{Physical properties of clasp materials}

Various metallic materials have been used to fabricate the clasps of PRDPs and the physical properties of these materials have been examined [6, 22, 25, 39-41, 49, 51-53, 63]. The most common alloys used for clasps are cobalt-chromium (CoCr) alloys [63].

CoCr alloy has a value for modulus of elasticity (stiffness) indicated by the steepness of the first part of the black curve, which is twice that of gold alloy (Fig. 3). Thus, under identical conditions the force required to deflect the cobalt chromium clasp over the bulbosity of the tooth will be twice that of a gold clasp [12].

Of particular importance is the proportional limit of the alloy indicated by the solid circles on the curves. If a clasp is stressed beyond the proportional limit it will be distorted permanently. Hard gold and cobalt chromium have similar proportional limits. Hardened stainless steel wire (blue curve) has a much higher value [12].

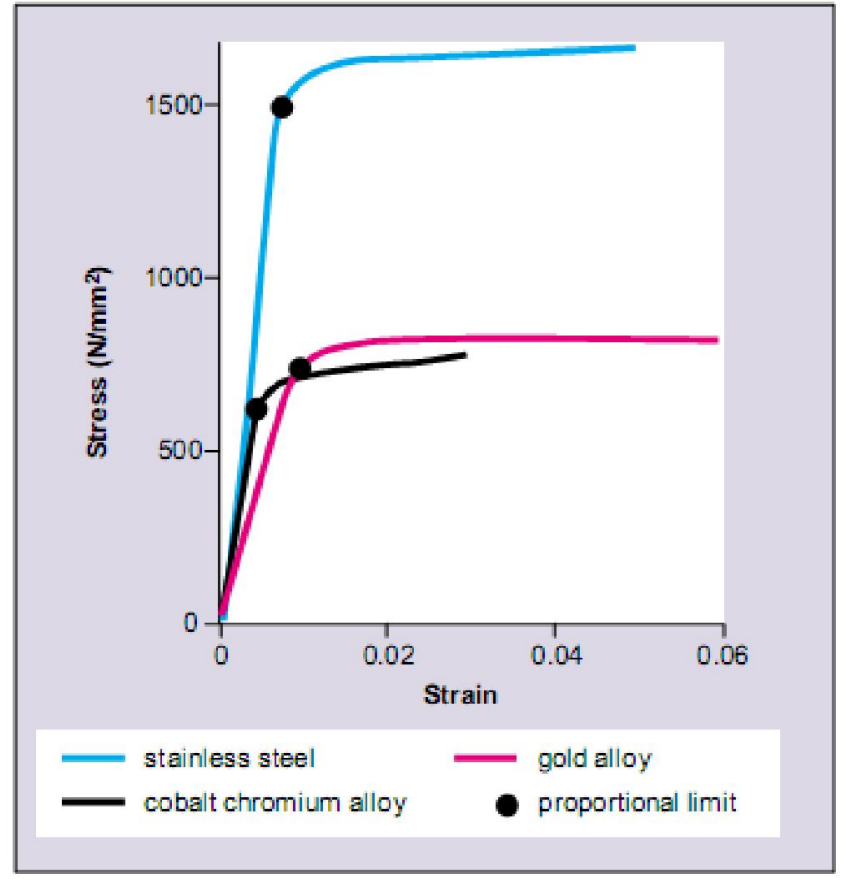

Fig. 3. Stress strain curve CoCr alloy, gold alloy and stainless steel [12]. 


\subsubsection{Fatigue test}

Fatigue is the loss of strength and other important properties as a result of stressing a material over a quite long period of time. Fatigue is very important, as it is the single largest cause of failures in metals, estimated as about $90 \%$ of metallic failures; polymers and ceramics are also susceptible to this type of failure.

Clasps undergo permanent deformation to cause fatigue fracture under repeated flexures during denture insertion and removal, and masticatory actions [9, 32]. Permanent deformation and fatigue fracture are caused by the stress created in the clasp [23, 62]. The stress distribution may depend on the elastic modulus of the alloy, dimensions and curvature of the clasp [54, 68], and amount and direction of deflection in relation to the abutment undercut [51].

There have been studies that investigated the retention properties of $\mathrm{CoCr}$ alloys using repeated insertion/removal tests. Rodriguez et al. indicated an increase in retentive force during the simulation test [49], while retention decrease was reported by Bridgeman et al. [6] and Kim et al. [33].

Retentive clasp arms must be flexible and should retain the PRDP satisfactorily. In addition, clasps should not unduly stress abutment teeth or be permanently distorted during service [35]. Previous studies indicated that PRDP clasps made of more elastic materials like titanium and gold demonstrated a higher resistance to retention loss [33, 35].

Mahmoud et al. [40] investigated gold alloy and Ti6Al7Nb, which were subjected to cyclic deflection of pre-set values of $0.25,0.50$, and $0.75 \mathrm{~mm}$ for 106 cycles. It was concluded that the gold alloy clasps exhibited significantly longer fatigue lifes, while the Ti6Al7Nb clasps showed significantly greater resistance to permanent deformation under cyclic deflection [40].

The fatigue resistances of experimentally prepared NiTi $(50.8 \% \mathrm{Ni}-49.2 \% \mathrm{Ti})$ cast clasps as well as $\mathrm{CpTi}, \mathrm{CoCr}$ alloy, and $\mathrm{AuAgPdCu}$ alloy clasps were evaluated in a simulated clinical situation [35]. The change in force required to remove the NiTi clasps was recorded under a repeated placement-removal test on steel model abutment teeth. The tips of the clasps were located in a 0.25 and $0.5 \mathrm{~mm}$ undercut area of the abutments. It was found that (1) no significant change in the retentive force was found in NiTi clasps during 1010 repeated 
cycles, but (2) the other three types of clasps revealed a significant decrease in the force required for removal during the test [35].

\subsubsection{Ther moplastic resins and PRDPS}

Polyoxymethylene (POM) was used for the construction of retentive and supportive components of partial removable dental prostheses (PRDPs) to improve aesthetics. Since the introduction of POMs, there has been a continued interest in its use for PRDP applications [1, 10, 20, 37, 48, 61]. Chu considered it a simple and effective means of improving PRDP aesthetics [10]. Polyacetal resin clasps (POM clasps) were also suggested for use instead of the metal clasps during radiation therapy to prevent backscatter from radiation [58].

The design, retentive force, colour stability, water sorption and solubility of POM clasps have been investigated. Arda and Arikan performed an in vitro study to compare the retentive force and deformation of POM and cobalt-chromium clasps [1]. They found that the mean dislodgement force for POM clasps was significantly lower than that for $\mathrm{CoCr}$ clasps. However, flexibility of POM clasps would allow for the retentive clasp arms of PRDPs to be placed in deeper undercuts on abutments. Further, the flexibility and long-term retentive resiliency of the clasps suggest that POM clasps may be suitable for PRDPs when aesthetics or periodontal health is of primary concern.

Turner et al. examined the flexural properties of POM to determine the appropriate design for the POM clasps [61]. They also evaluated the effectiveness of various POM polishing procedures. They suggested that a suitable POM clasp must be approximately $5 \mathrm{~mm}$ shorter than $\mathrm{CoCr}$ clasps with a larger cross-sectional diameter (approximately $1.4 \mathrm{~mm}$ ) in order to have the stiffness similar to a cast CoCr clasp $15 \mathrm{~mm}$ long and $1 \mathrm{~mm}$ in diameter.

Arikan et al. compared water sorption and water solubility of pink and white acetal resin to a heatpolymerized polymethyl methacrylate resin (PMMA) [2]. The result showed that pink acetal resin had significantly lower water sorption than PMMA and white acetal resin. PMMA showed higher solubility than pink and white POM.

Ozkan et al. also did a study to access the colour stability of polyacetal resin subjected to thermocycling and showed it has clinically acceptable discolouration values [46]. 
However, to the best knowledge of the author there are no studies evaluating the use of PEEK and PEKK as clasp materials. Due to the low modulus of elasticity (2-4 GPa) [36, 61], thermoplastic resin has superior flexibility compared to the conventional $\mathrm{CoCr}$ alloys. The increased flexibility of a resin direct retainer permits its placement more cervically without deformation or producing more stress on the abutment teeth which is of importance for improved esthetics and predictable long-term use of a PRDP [54]. 


\subsection{Purpose of the study}

This in-vitro study investigated the retentive force of different thermoplastic resin clasps during repetitive placement and removal on abutment teeth with two different thicknesses and two amounts of undercut. Conventional CoCr clasps were included as control group. The null hypothesis was that there would be no difference in the retentive force between resin clasps and cast CoCr alloy clasps. 


\section{M aterials and methods}

Three thermoplastic resins (POM, PEEK and PEKK) and a conventional $\mathrm{CoCr}$ alloy were evaluated in this study.

All used materials are presented in Table 1.

Table 1. Materials used for clasp fabrication

\begin{tabular}{llll}
\hline Brand name & Composition & Manufacturer & Batch number \\
\hline Acetal Dental & Polyoxymethylene & Dental Srl, San Marino, & 01065 \\
& $(\mathrm{POM})$ & Italy & \\
Bio XS & Polyetheretherketon & Bredent, Senden, & 540XS016901 \\
& $($ PEEK) & Germany & \\
PEKKtone A & Polyetherketonketon & Cendres Metaux, Bienne, X1074M \\
& $($ PEKK $)$ & Switzerland & \\
Wironit & Co 64 \%; Cr 28,6\%; Mo & Bego, Bremen, Germany & 12769 \\
& $5 \%(\mathrm{CoCr})$ & & \\
\hline
\end{tabular}

\subsection{A butment fabrication}

An artificial maxillary first premolar (KaVo, Biberach, Germany) was embedded in autopolymerizing acrylic resin (Technovit 4000; Heraeus-Kulzer, Wehrheim, Germany) using custom-made copper holders with a diameter of $15 \mathrm{~mm}$.

The maxillary first premolar was prepared for a surveyed complete metal crown. The prepared premolar was dublicated twice using a polyether impression material (Impregum Penta $\mathrm{H}$ and L; 3M Espe, Seefeld, Germany). The impressions were poured in type IV stone (GC Fujirock EP; GC, Leuven, Belgium), and a complete crown was waxed on each preparation (Crowax; Renfert GmbH, Hilzingen, Germany).

The waxed crowns were surveyed to provide an undercut of $0.25 \mathrm{~mm}$ on one crown and 0.50 $\mathrm{mm}$ on the other. Occlusal rests, $2.5 \mathrm{~mm}$ long, $2.5 \mathrm{~mm}$ wide, and $2 \mathrm{~mm}$ deep, were placed mesially. Mesial and lingual guide planes, two thirds the length of the crown, were prepared 
with a surveyor blade to standardize the path of insertion. The waxed two crowns were duplicated with silicon material (Speedy Wax Transpaduplisil 101; Zahntechnik Norbert Wichnalek, Augsburg, Germany), and then 16 crowns with $0.25 \mathrm{~mm}$ undercut and 16 with $0.50 \mathrm{~mm}$ undercut were made by inserting heated liquid wax (Speedy Wax Injektionswachs 70; Zahntechnik Norbert Wichnalek) into the silicone mold. Then the crowns were cast in CoCr alloy (Wironit 99; Bego, Bremen, Germany).

After fitting and finishing, the crowns were cemented in place on the abutments with zinc phosphate cement (Hoffmann quick setting, Hoffmann, Berlin, Germany). The guide planes were evaluated for parallelism.

\subsection{Clasp fabrication}

To standardize the position of clasp arm undesirable undercut areas were blocked out with the sculpturing wax (Crowax, Renfert, Hilzingen, Germany) with approximately $2 \mathrm{~mm}$ surrounding thickness. Impressions of each model were made in polyether impression material (Impregum Penta $\mathrm{H}$ and $\mathrm{L}$ ) with custom impression trays.

\subsubsection{CoCr Clasps}

The impressions were poured with die-investment material (Obtivest, DeguDent, Hanau, Germany) to make refractory casts for the CoCr clasps.

Preformed half-round tapered clasp patterns (1.0 mm thick) with occlusal rests, and retentive and reciprocal arms (Wachsprofile, Bego) (Fig. 4) were adapted along the ledges formed with block-out material prior to making definitive impressions. A round wax sprue was connected to the residual ridge base parallel to the path of insertion using a surveyor. This sprue was later used to maintain clasp test specimens in the masticatory simulator.

Each assembly (die and pattern) was invested (Obtivest, DeguDent) according to the manufacturer's instructions and cast in $\mathrm{CoCr}$ alloy. Finally the clasps were trimmed, airborneparticle abraded with $50 \mu \mathrm{m}$ alumina at $0.25 \mathrm{MPa}$ pressure. To ensure uniformity of clasps, no polishing was performed. 


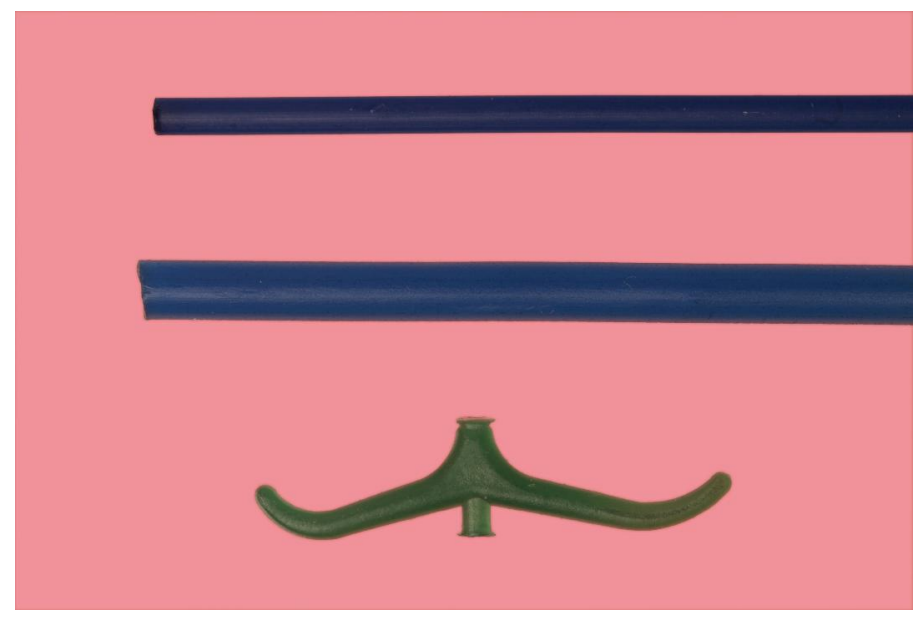

A: Straight half-round clasp pattern $(1 \times 2 \mathrm{~mm})$

B: Straight half-round wax pattern $(1.5 \times 3 \mathrm{~mm})$

C: Tapered half-round clasp pattern $(1 \times 1.4 \mathrm{~mm})$

Fig. 4. Wax patterns used to make the clasps.

\subsubsection{POM clasps}

The impressions were poured with Type IV dental stone (Marble Stone; Dental Srl, San Marino, Italy) to make refractory casts.

For fabrication of the $1.0 \mathrm{~mm}$ and $1.5 \mathrm{~mm}$ thick thermoplastic resin clasps straight semicircular clasp patterns (Wax patterns, Omnident, Rodgau Nieder-Roden, Germany) (Fig. 4) were used. The previously described wax sprue was connected to the residual ridge base parallel to the path of insertion using a surveyor.

First, the assembly (stone model and clasp pattern) was placed at a distance of approximately $2.5 \mathrm{~cm}$ from the injection opening of the special flask (Muffle-Type 100; Pressing Dental Srl) with Type IV dental stone (GC Fujirock EP, GC). When the flask was set-up, it was reopened and the wax is removed with boiling water. The flask is closed again and placed into an oven at $100^{\circ} \mathrm{C}$ for 30 minutes.

POM cylinders were placed into the injection sleeve, teflon plunger was placed into the sleeve on top of the resin material and pushed down, and then the sleeve was placed in the injection machine (J-100; Pressing Dental Srl) (Fig. 5). The parameters of the injection machine were set as follows: pre-injection time with the material maintained at $220^{\circ} \mathrm{C}$ (melting temperature) for 20 minutes, post-injection time with the temperature maintained at the desired level of 
$220^{\circ} \mathrm{C}$ for 5 minutes, injection cooling for 60 minutes, and injection pressure of 4 bar. At the end of the process, the flask was removed from the initial position, and the clasp was deflasked.

Injection settings of POM*:

\begin{tabular}{ll}
\hline Pre-heating temperature/time & $100^{\circ} \mathrm{C} / 30 \mathrm{~min}$ \\
Melting temperature & $220^{\circ} \mathrm{C}$ \\
Pre-injection time & $20 \mathrm{~min}$ \\
Injection pressure & $4 \mathrm{bar}$ \\
Post-injection time & $5 \mathrm{~min}$ \\
Cooling time & $60 \mathrm{~min}$ \\
Injection device & $\mathrm{J}-100 ;$ Pressing Dental Srl, San Marino, Italy \\
\hline
\end{tabular}

*according to the manufacturer

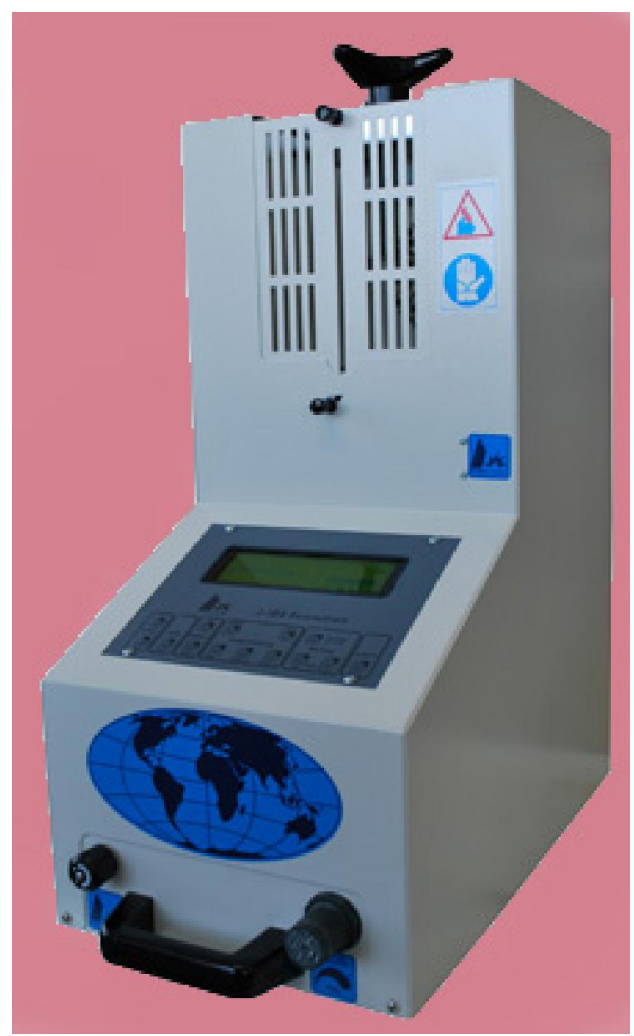

Fig. 5. Injection machine (J-100). 


\subsubsection{PEEK clasps}

The impressions were with poured Type IV dental stone (Expando-Rock; Bredent, Senden, Germany) to make refractory casts.

For fabrication of the $1.0 \mathrm{~mm}$ and $1.5 \mathrm{~mm}$ thick thermoplastic resin clasps straight semicircular clasp patterns (Wax patterns, Omnident) (Fig. 4) were used. The previously described wax sprue was connected to the residual ridge base parallel to the path of insertion using a surveyor.

First, the assembly (stone model and clasp pattern) was placed at a distance of approximately $2.5 \mathrm{~cm}$ from the injection opening of the special flask (Thermopress flask N; Bredent) with Type IV dental stone (GC Fujirock EP, GC). When the flask was set-up, it was reopened and the wax is removed with boiling water. The flask is closed again and placed into an oven at $200^{\circ} \mathrm{C}$ for 20 minutes.

The injection sleeve filled with PEEK was placed in the injection machine (Thermopress 400 injection moulding system; Bredent) (Fig. 6). The parameters of the injection machine were set as follows: pre-injection time with the material maintained at $380^{\circ} \mathrm{C}$ (melting temperature) for 25 minutes, post-injection time with the temperature maintained at the desired level of $220^{\circ} \mathrm{C}$ for 2 minutes, injection cooling for 60 minutes, and injection pressure of 4 bar. At the end of the process, the flask was removed from the initial position, and the clasp was deflasked.

Injection settings of PEEK*:

\begin{tabular}{ll}
\hline Pre-heating temperature/time & $200^{\circ} \mathrm{C} / 20 \mathrm{~min}$ \\
Melting temperature & $380^{\circ} \mathrm{C}$ \\
Pre-injection time & $25 \mathrm{~min}$ \\
Injection pressure & $4 \mathrm{bar}$ \\
Post-injection time & $2 \mathrm{~min}$ \\
Cooling time & $60 \mathrm{~min}$ \\
Injection device & Thermopress 400 injection moulding system; Bredent \\
\hline
\end{tabular}

*according to the manufacturer 


\subsubsection{PEKK clasps}

The impressions were poured with die-investment material (Obtivest, DeguDent, Hanau, Germany) to make refractory casts.

For fabrication of the $1.0 \mathrm{~mm}$ and $1.5 \mathrm{~mm}$ thick thermoplastic resin clasps straight semicircular clasp patterns (Wax patterns, Omnident) (Fig. 4) were used. The previously described wax sprue was connected to the residual ridge base parallel to the path of insertion using a surveyor.

Each assembly (die and pattern) was invested (Obtivest, DeguDent) according to the manufacturer's instructions using a special muffle (thermopress 400 Muffel-System, Bredent).

The injection procedure was performed using the injection machine (Thermopress 400 injection moulding system; Bredent) (Fig. 6). The parameters of the injection machine were set as follows: pre-injection time with the material maintained at $325^{\circ} \mathrm{C}$ (melting temperature) for 20 minutes, post-injection time with the temperature maintained at the desired level of $325^{\circ} \mathrm{C}$ for 1 minutes, injection cooling for 60 minutes, and injection pressure of 7 bar. At the end of the process, the flask was removed from the initial position, and the clasp was deflasked.

Injection settings of PEKK*:

\begin{tabular}{ll}
\hline Pre-heating temperature/time & $150^{\circ} \mathrm{C} / 30 \mathrm{~min}$ \\
Melting temperature & $325^{\circ} \mathrm{C}$ \\
Pre-injection time & $20 \mathrm{~min}$ \\
Injection pressure & $7 \mathrm{bar}$ \\
Post-injection time & $1 \mathrm{~min}$ \\
Cooling time & $60 \mathrm{~min}$ \\
Injection device & Thermopress 400 injection moulding system; Bredent \\
\hline
\end{tabular}

*according to the manufacturer

Eight clasps were fabricated for each material, clasp size, and retentive undercut combination. A total of 112 clasps were made, including 16 CoCr clasps as control group (Fig. 7). 
Materials and methods

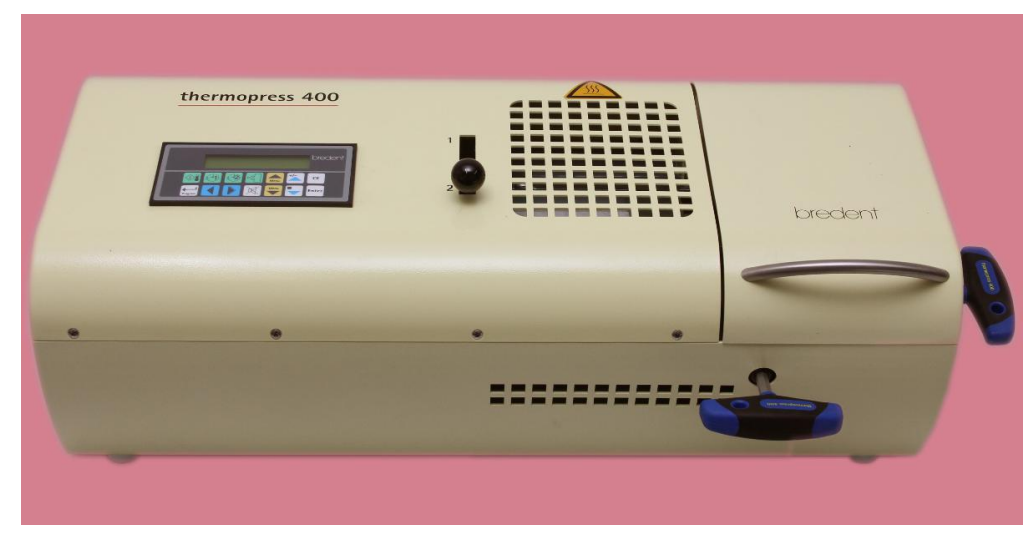

Fig. 6. Injection machine (Thermopress 400). 
Materials and methods

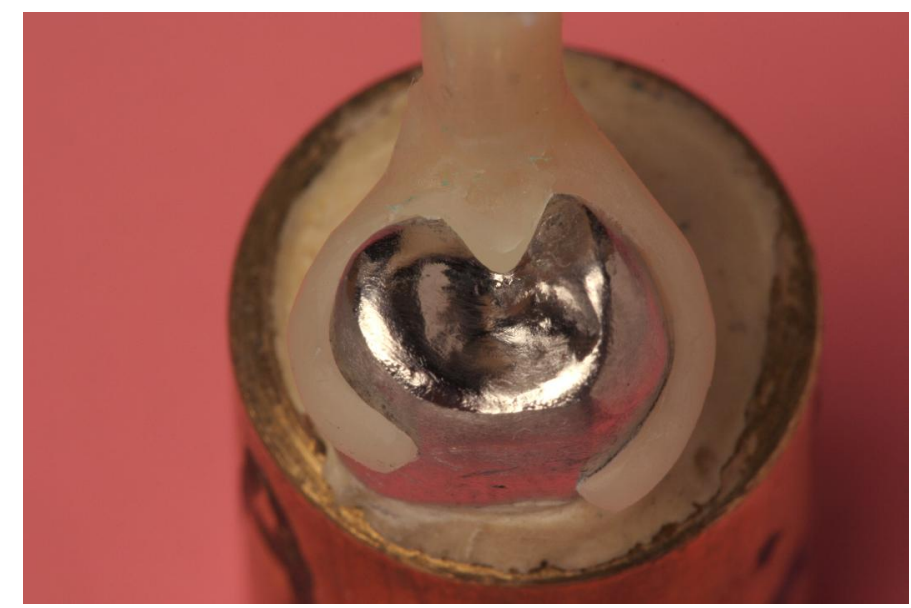

A: Thermoplastic resin clasp $1 \mathrm{~mm}$

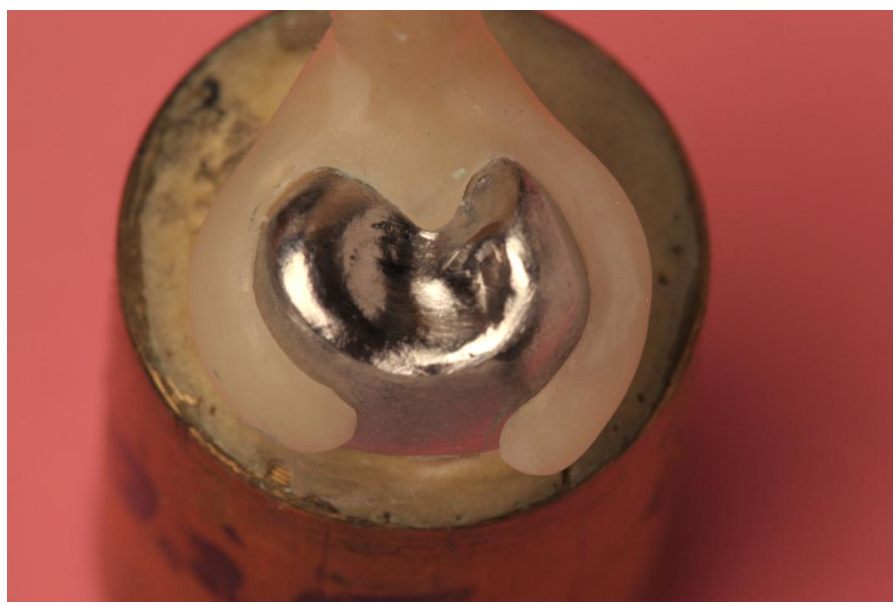

B: Thermoplastic resin clasp $1.5 \mathrm{~mm}$

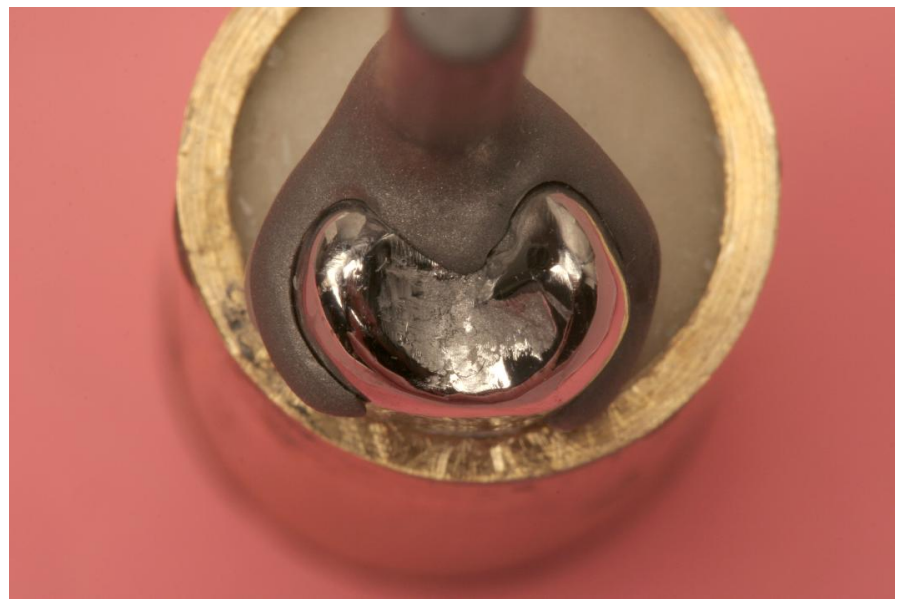

C: CoCr clasp $1 \mathrm{~mm}$

Fig. 7. Clasps on their abutment models. 


\subsection{T est conditions}

To perform the retention test, a masticatory simulator (Willytec, Munich, Germany) (Fig. 8) was used. The machine allowed the placement of the clasp to its predetermined terminal position and its subsequent removal from the abutment crown, thus simulating the placement and removal of a PRDP. The models with the crowns were mounted in the masticatory simulator. Each clasp specimen was then placed on the corresponding abutment crown and fixed to the upper part of machine with auto-polymerizing acrylic resin (Technovit 4000, Heraeus-Kulzer) (Fig. 9). The test conditions were maintained at room temperature $\left(20 \pm 2{ }^{\circ} \mathrm{C}\right)$ and wet condition (deionised water). To analyze the data obtained during the simulation test, intervals every 1,500 cycles were established. A total of 15,000 cycles were performed, representing the simulated insertion and removal of the PRDP over 10 years, estimating that the patient would perform four removals and insertions of the PRDP per day. The test was performed at a constant speed of $8 \mathrm{~mm} / \mathrm{s}$. The value established for each time interval corresponded to the arithmetic average of 10 consecutive insertion/removal cycles. The force required for each specimen removal was captured and stored using data acquisition software (LabView, National Instrument, Munich, Germany). Statistical analysis was done with fourway and two-way analyses of variance (ANOVA). Significance level was set at 5\% ( $\alpha=$ $0.05)$. 


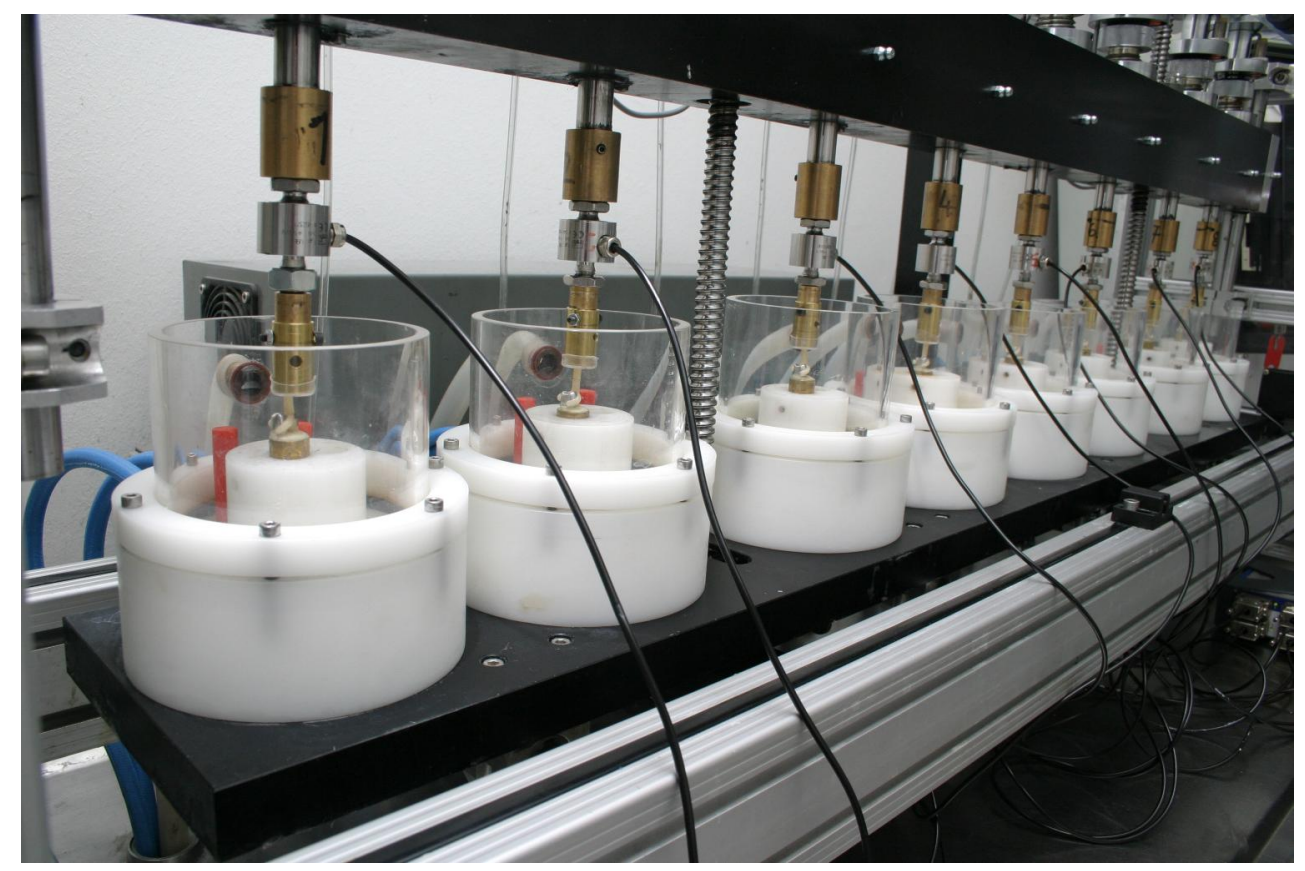

Fig. 8. Computer controlled masticatory simulator with mounted specimen in eight trial cells.

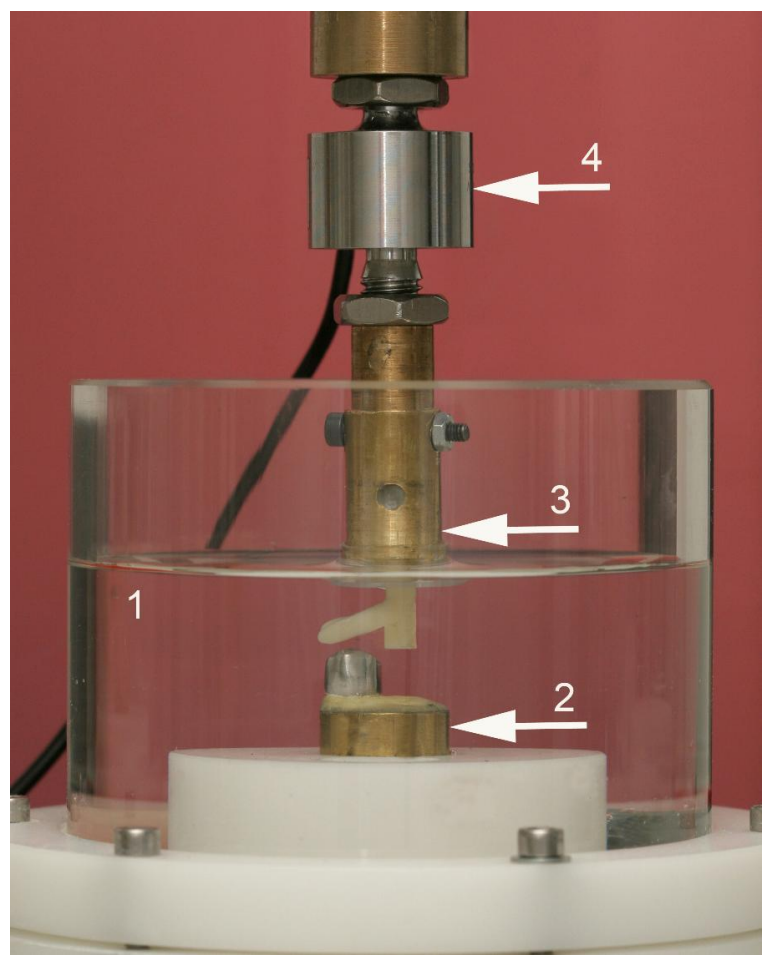

Fig. 9. Test set-up in a loading chamber of masticatory simulator. (1) loading chambers filled with water, (2) holder with abutment crown, (3) holder with the clasp, and (4) force transducer. 


\section{Results}

Tables 2 and 3 show the mean retention forces for all subgroups at all test intervals. The mean initial retentive force ranged from 1.2 to $3.1 \mathrm{~N}$ for the $1.0 \mathrm{~mm}$ thick resin clasps and from 4.9 to $9.1 \mathrm{~N}$ for the $1.5 \mathrm{~mm}$ thick resin claps. For CoCr clasps it ranged from 11.3 to $16.3 \mathrm{~N}$. The highest initial retentive force $(16.3 \mathrm{~N})$ was recorded in the $\mathrm{CoCr}$ clasps with $0.50 \mathrm{~mm}$ undercut, and the lowest retentive force $(1.2 \mathrm{~N})$ was measured in the $1.0 \mathrm{~mm}$ POM clasps with $0.25 \mathrm{~mm}$ undercut.

After 15,000 insertion-removal cycles the mean retentive force ranged from 1.2 to $3.2 \mathrm{~N}$ for the $1.0 \mathrm{~mm}$ thick resin clasps and from 4.8 to $9.0 \mathrm{~N}$ for the $1.5 \mathrm{~mm}$ thick resin claps. For $\mathrm{CoCr}$ clasps it ranged from 11.8 to $16.3 \mathrm{~N}$. The highest final retentive force $(16.3 \mathrm{~N})$ was recorded in the $\mathrm{CoCr}$ clasps with $0.50 \mathrm{~mm}$ undercut, and the lowest retentive force $(1.2 \mathrm{~N})$ was measured in the $1.0 \mathrm{~mm}$ POM clasps with $0.25 \mathrm{~mm}$ undercut.

Figures 10 and 11 show the changes in retentive force required to remove clasps from the 0.25 $\mathrm{mm}$ and $0.50 \mathrm{~mm}$ undercuts. 
Table 2. Mean retention forces $(\mathrm{N})$ for all subgroups with $0.25 \mathrm{~mm}$ undercuts at the different time intervals.

\begin{tabular}{ccccrrrrr}
\hline Intervals & CoCr & PEEK & PEEK & PEKK & PEKK & POM & POM \\
& $1.0 \mathrm{~mm}$ & $1.0 \mathrm{~mm}$ & $1.5 \mathrm{~mm}$ & $1.0 \mathrm{~mm}$ & $1.5 \mathrm{~mm}$ & $1.0 \mathrm{~mm}$ & $1.5 \mathrm{~mm}$ \\
\hline 0 cycle & 11.3 & 1.7 & 6.7 & 1.8 & 5.6 & 1.2 & 4.9 \\
1500 cycles & 13.9 & 2.6 & 7.5 & 2.2 & 6.0 & 1.7 & 5.4 \\
3000 cycles & 13.6 & 2.3 & 7.2 & 2.1 & 5.6 & 1.6 & 5.5 \\
4500 cycles & 13.3 & 2.3 & 7.1 & 2.1 & 5.5 & 1.5 & 5.4 \\
6000 cycles & 13.1 & 2.3 & 7.0 & 2.0 & 5.4 & 1.5 & 5.2 \\
7500 cycles & 12.9 & 2.2 & 7.0 & 2.0 & 5.3 & 1.5 & 5.1 \\
9000 cycles & 12.7 & 2.2 & 6.9 & 1.9 & 5.2 & 1.4 & 5.0 \\
10500 cycles & 12.5 & 2.1 & 6.7 & 1.9 & 5.1 & 1.4 & 4.9 \\
12000 cycles & 12.2 & 2.1 & 6.7 & 1.9 & 5.0 & 1.4 & 4.9 \\
13500 cycles & 12.1 & 2.0 & 6.6 & 1.8 & 4.9 & 1.2 & 4.8 \\
15000 cycles & 11.8 & 1.9 & 6.5 & 1.5 & 4.9 & 1.2 & 4.8 \\
\hline
\end{tabular}

Table 3. Mean retention forces $(\mathrm{N})$ for all subgroups with $0.5 \mathrm{~mm}$ undercuts at the different time intervals.

\begin{tabular}{crrrrrrr}
\hline Intervals & $\begin{array}{c}\text { COCr 1.0 } \\
\mathrm{mm}\end{array}$ & $\begin{array}{c}\text { PEEK } \\
1.0 \mathrm{~mm}\end{array}$ & $\begin{array}{c}\text { PEEK } 1.5 \\
\mathrm{~mm}\end{array}$ & $\begin{array}{c}\text { PEKK } \\
1.0 \mathrm{~mm}\end{array}$ & $\begin{array}{c}\text { PEKK } \\
1.5 \mathrm{~mm}\end{array}$ & $\begin{array}{c}\text { POM } \\
1.0 \mathrm{~mm}\end{array}$ & $\begin{array}{c}\text { POM } \\
1.5 \mathrm{~mm}\end{array}$ \\
\hline 0 cycle & 16.3 & 3.0 & 8.6 & 3.1 & 9.1 & 1.7 & 6.6 \\
1500 cycles & 19.8 & 3.7 & 11.0 & 3.6 & 9.9 & 2.0 & 7.3 \\
3000 cycles & 19.3 & 3.7 & 10.8 & 3.6 & 9.4 & 2.0 & 7.4 \\
4500 cycles & 18.9 & 3.6 & 10.7 & 3.5 & 9.2 & 1.9 & 7.3 \\
6000 cycles & 18.5 & 3.5 & 10.7 & 3.5 & 9.1 & 1.9 & 7.2 \\
7500 cycles & 18.1 & 3.5 & 10.5 & 3.4 & 9.0 & 1.9 & 7.1 \\
9000 cycles & 17.8 & 3.5 & 10.4 & 3.4 & 8.8 & 1.9 & 7.0 \\
10500 cycles & 17.4 & 3.4 & 10.1 & 3.3 & 8.7 & 1.8 & 6.9 \\
12000 cycles & 16.9 & 3.4 & 9.8 & 3.2 & 8.6 & 1.8 & 6.8 \\
13500 cycles & 16.7 & 3.3 & 9.4 & 3.2 & 8.4 & 1.8 & 6.7 \\
15000 cycles & 16.3 & 3.2 & 9.0 & 3.2 & 8.3 & 1.6 & 6.6 \\
\hline
\end{tabular}




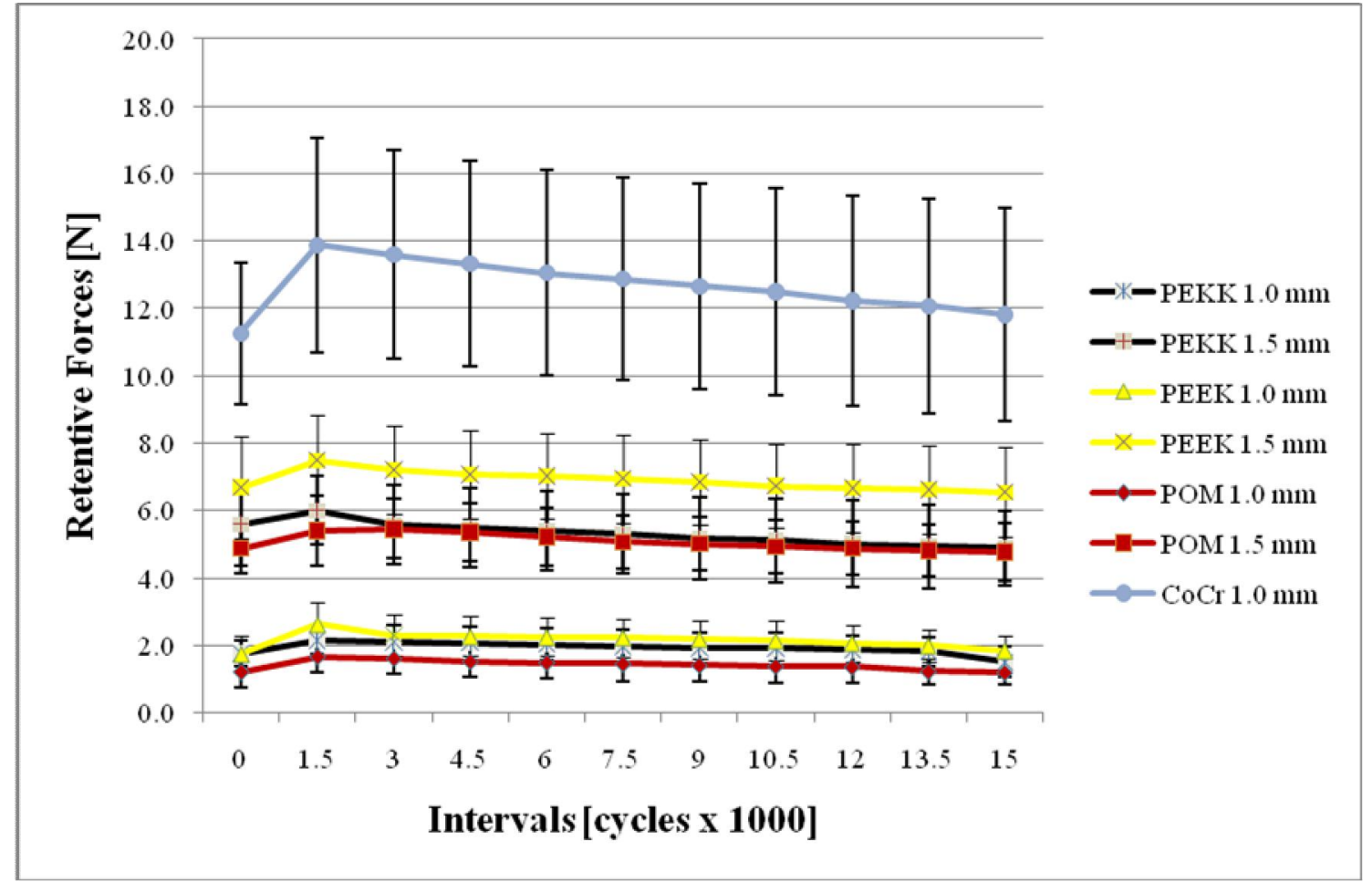

Fig. 10. Change in forces required to remove clasps in groups with $0.25 \mathrm{~mm}$ undercut.

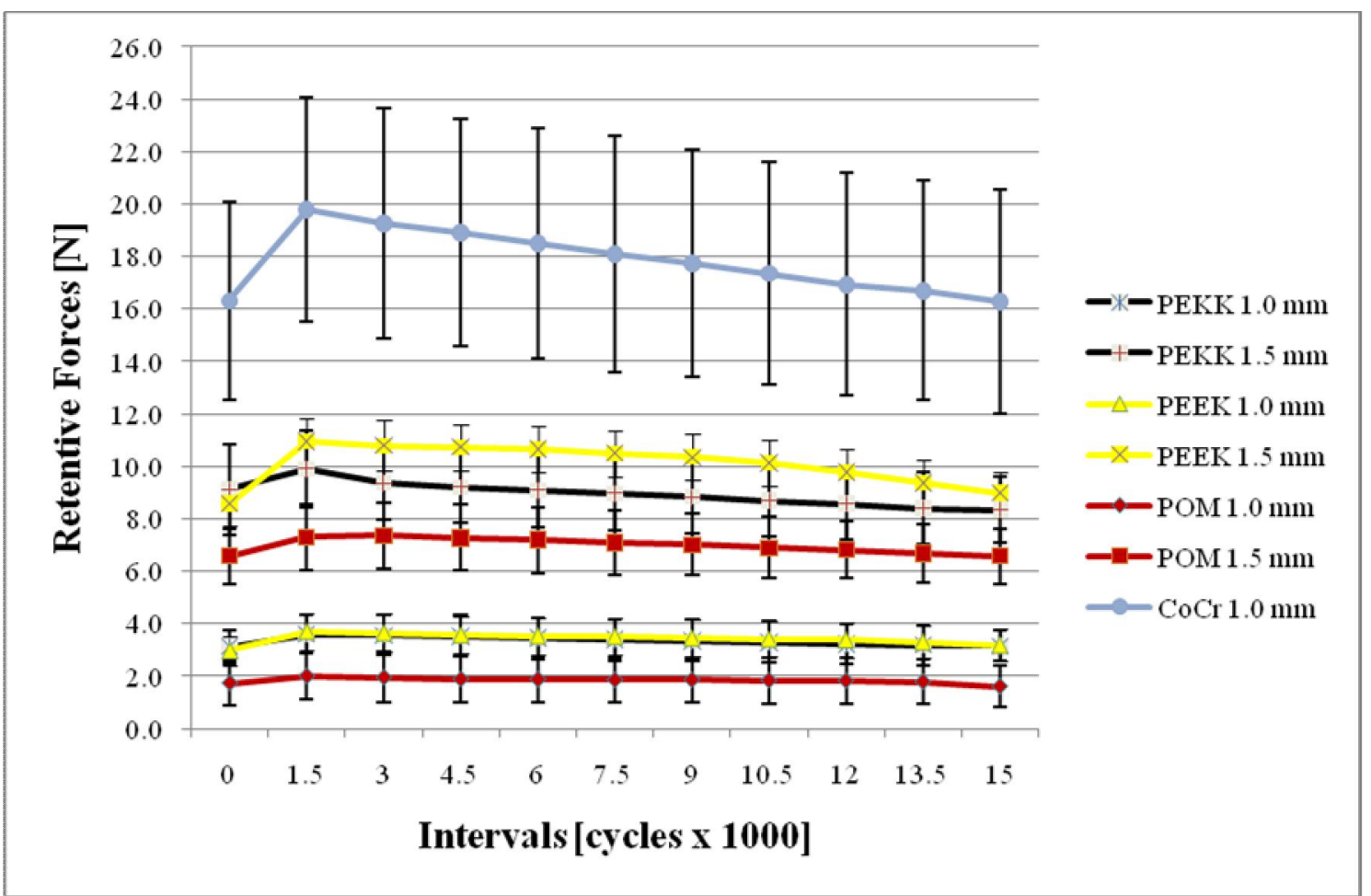

Fig. 11. Change in forces required to remove clasps in groups with $0.50 \mathrm{~mm}$ undercut. 
Results of the 4-way ANOVA for the resin clasps indicated a significant influence of the three tested factors (material, thickness, and undercut) on the mean retention force (P $₫ .001$ ). PEEK exhibited the highest retention followed by PEKK and POM (P $₫ .001$ ). The retentive force required to dislodge $1.5 \mathrm{~mm}$ thick resin clasps was significantly higher than the retentive force needed for $1.0 \mathrm{~mm}$ thick clasps. Also the amount of undercuts showed a significant effect on clasps retention with the $0.50 \mathrm{~mm}$ undercut provided the higher retention, while there was no significant influence of the cycling factor on the mean retention force $(\mathrm{P}>0.05)$ (Table 4). However, 2 significant interactions were found between (a) undercut and material and (b) undercut and thickness. Therefore, a 2-way ANOVA was performed separately for each undercut.

Table 4. Comparison between mean retention forces (PEEK, PEKK, POM) using 4-way ANOVA

\begin{tabular}{|c|c|c|c|c|c|}
\hline Source & $\begin{array}{l}\text { Type III sum } \\
\text { of squares }\end{array}$ & $\mathrm{df}$ & $\begin{array}{l}\text { M ean } \\
\text { square }\end{array}$ & $F$ & Sig. \\
\hline Material & 75.990 & 2 & 37.995 & 41.501 & $<.000$ \\
\hline Undercut & 153.189 & 1 & 153.189 & 167.323 & $<.000$ \\
\hline Thickness & 1074.940 & 1 & 1074.940 & 1174.120 & $<.000$ \\
\hline Time & .248 & 1 & .248 & .271 & .603 \\
\hline Material x Undercut & 14.831 & 2 & 7.416 & 8.100 & $<.000$ \\
\hline Material x Thickness & 9.013 & 2 & 4.506 & 4.922 & .078 \\
\hline Material x Time & 2.914 & 2 & 1.457 & 1.591 & .207 \\
\hline Undercut $\mathrm{x}$ Thickness & 27.376 & 1 & 27.376 & 29.902 & .000 \\
\hline Undercut $\mathrm{x}$ Time & .278 & 1 & .278 & .303 & .583 \\
\hline Thickness x Time & .234 & 1 & .234 & .255 & .614 \\
\hline $\begin{array}{l}\text { Material x Undercut x } \\
\text { Thickness }\end{array}$ & 2.579 & 2 & 1.290 & 1.409 & .247 \\
\hline Material x Undercut x Time & .968 & 2 & .484 & .528 & .591 \\
\hline Material x Thickness $\mathrm{x}$ Time & 1.020 & 2 & .510 & .557 & .574 \\
\hline $\begin{array}{l}\text { Undercut x Thickness } \mathrm{x} \\
\text { Time }\end{array}$ & .431 & 1 & .431 & .471 & .493 \\
\hline $\begin{array}{l}\text { Material x Undercut x } \\
\text { Thickness x Time }\end{array}$ & .534 & 2 & .267 & .292 & .747 \\
\hline Error & 153.809 & 168 & .916 & & \\
\hline Total & 5360.590 & 192 & & & \\
\hline
\end{tabular}


The 2-way ANOVA of the both undercuts revealed a significant effect of the material and thickness on the mean retention force (Tables 5 and 6). However, comparisons of the means of the three tested resin materials POM, PEKK, and PEEK, with the Tukey multiple range test showed no significant difference between POM and PEKK at $0.25 \mathrm{~mm}$ undercut, while at $0.50 \mathrm{~mm}$ undercut, there was no significant difference between PEKK and PEEK (Tab. 7).

Table 5. Summary of 2-way ANOVA for the $0.25 \mathrm{~mm}$ undercut

\begin{tabular}{lccccc}
\hline Source & $\begin{array}{c}\text { Typelll sum of } \\
\text { squares }\end{array}$ & $\mathrm{df}$ & M ean square & $\mathrm{F}$ & Sig. \\
& 18.913 & 2 & 9.457 & 12.039 & $<.000$ \\
\hline Material & 388.621 & 1 & 388.621 & 494.755 & $<.000$ \\
Thickness & 6.680 & 2 & 3.340 & 4.252 & .117 \\
Material x Thickness & .901 & 1 & .901 & 1.147 & .287 \\
Thickness x Time & 66.766 & 85 & .785 & & \\
Error & 1745.230 & 97 & & & \\
Total & & & & & \\
\hline
\end{tabular}

Table 6. Summary of 2-way ANOVA for the $0.50 \mathrm{~mm}$ undercut

\begin{tabular}{lccccc}
\hline Source & $\begin{array}{l}\text { Type Ill sum of } \\
\text { squares }\end{array}$ & & M ean square & $F$ & Sig. \\
& 70.771 & 2 & 35.386 & 33.357 & $<.000$ \\
Material & 722.704 & 1 & 722.704 & 681.260 & $<.000$ \\
Thickness & 4.508 & 2 & 2.254 & 2.125 & .126 \\
Material x Thickness & .015 & 1 & .015 & .014 & .906 \\
Thickness x Time & 89.110 & 84 & 1.061 & & \\
Error & 3656.320 & 96 & & & \\
Total & &
\end{tabular}


Table 7. Comparison of the means of retention force with each undercut

\begin{tabular}{lcccc}
\hline & \multicolumn{2}{c}{ Undercut $0.25 \mathrm{~mm}$} & \multicolumn{2}{c}{ Undercut $0.5 \mathrm{~mm}$} \\
\hline POM & 3.1 & $\mathrm{~A}$ & 4.1 & $\mathrm{~A}$ \\
PEKK & 3.5 & $\mathrm{~A}$ & 5.9 & $\mathrm{~B}$ \\
PEEK & 4.1 & $\mathrm{~B}$ & 6.0 & $\mathrm{~B}$
\end{tabular}

Within the same column, means with same upper case letter are not significantly different.

The retentive force required for removal of the $1.5 \mathrm{~mm}$ thick resin clasps was significantly lower (P $₫$ (001) than that required for removal of the CoCr clasps with $0.25 \mathrm{~mm}$ and $0.50 \mathrm{~mm}$ undercuts (Tab. 8 and 9).

Table 8. Pair-wise comparison of the initial retentive values $(\mathrm{N})$ of $\mathrm{CoCr}$ clasps and $1.5 \mathrm{~mm}$ thick resin clasps

\begin{tabular}{cccccc}
\hline & \multicolumn{2}{c}{$0.25 \mathrm{~mm}$ undercut } & & \multicolumn{2}{c}{$0.50 \mathrm{~mm}$ undercut } \\
\cline { 2 - 3 } \cline { 5 - 6 } & M ean (SD) & $\mathrm{P}$ & & M ean (SD) & $\mathrm{P}$ \\
\hline CoCr 1.0 mm & $11.3(2.1)$ & $<.001$ & & $16.3(3.8)$ & $<.001$ \\
POM 1.5 mm & $4.9(0.7)$ & & & $6.6(1.1)$ & \\
CoCr 1.0 mm & $11.3(2.1)$ & .003 & & $16.3(3.8)$ & .001 \\
PEEK 1.5 mm & $6.7(1.5)$ & & & $8.6(1.2)$ & \\
CoCr 1.0 mm & $11.3(2.1)$ & $<.001$ & & $16.3(3.8)$ & .002 \\
PEKK 1.5 mm & $5.6(1.2)$ & & & $9.1(1.7)$ & \\
\hline
\end{tabular}

Table 9. Pair-wise comparison of the final retentive values $(\mathrm{N})$ of $\mathrm{CoCr}$ clasps and $1.5 \mathrm{~mm}$ thick resin clasps

\begin{tabular}{cccccc}
\hline & \multicolumn{2}{c}{$0.25 \mathrm{~mm}$ undercut } & & \multicolumn{2}{c}{$0.50 \mathrm{~mm}$ undercut } \\
\cline { 2 - 3 } \cline { 5 - 6 } & M ean (SD) & $\mathrm{P}$ & & M ean (SD) & $\mathrm{P}$ \\
\hline CoCr 1.0 mm & $11.8(3.2)$ & $<.001$ & & $16.3(4.3)$ & $<.001$ \\
POM 1.5 mm & $4.9(0.8)$ & & & $6.6(1.1)$ & \\
CoCr 1.0 mm & $11.8(3.2)$ & .003 & & $16.3(4.3)$ & .003 \\
PEEK 1.5 mm & $6.4(1.3)$ & & & $9.3(1.3)$ & \\
CoCr 1.0 mm & $11.8(3.2)$ & $<.001$ & & $16.3(4.3)$ & .002 \\
PEKK 1.5 mm & $4.9(1.1)$ & & & $8.5(1.3)$ & \\
\hline
\end{tabular}


All the clasps exhibited an increase in retentive forces during the first period of cycling followed by continuous decrease till the end of the cycling but it was still not significantly different compared to the initial retentive forces $(\mathrm{P}>0.05)$.

\section{SEM images}

After the cycling test the abutment models of $\mathrm{CoCr}$ groups showed some wear at contact area with the clasp tip, while no wear was detected on the models of resin claps. In addition, the inner surface of the clasp tip of all groups showed some amount of wear (Figures 12 and 13).

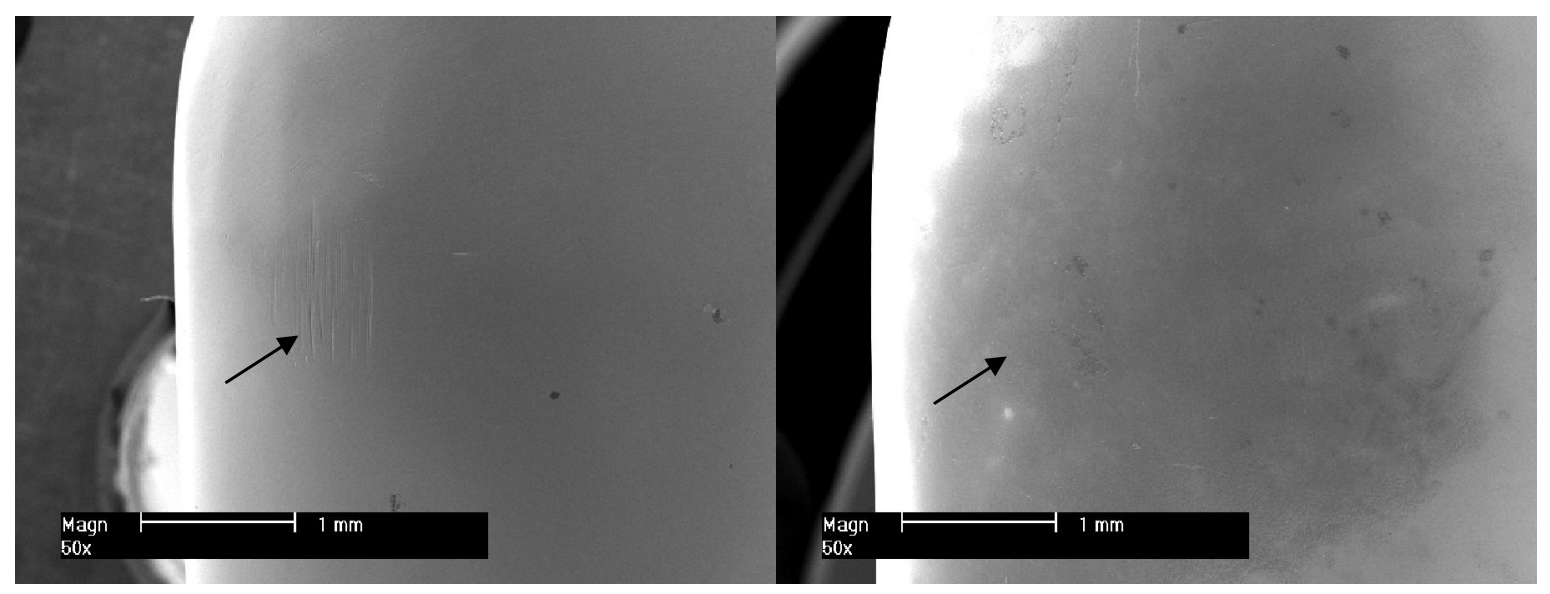

Fig. 12. SEM image of model surface at the contact area with the clasp tip (left: with CoCr clasp, right: with resin clasp). Arrows indicate some wear with $\mathrm{CoCr}$ clasps while no wear shown with resin clasps.

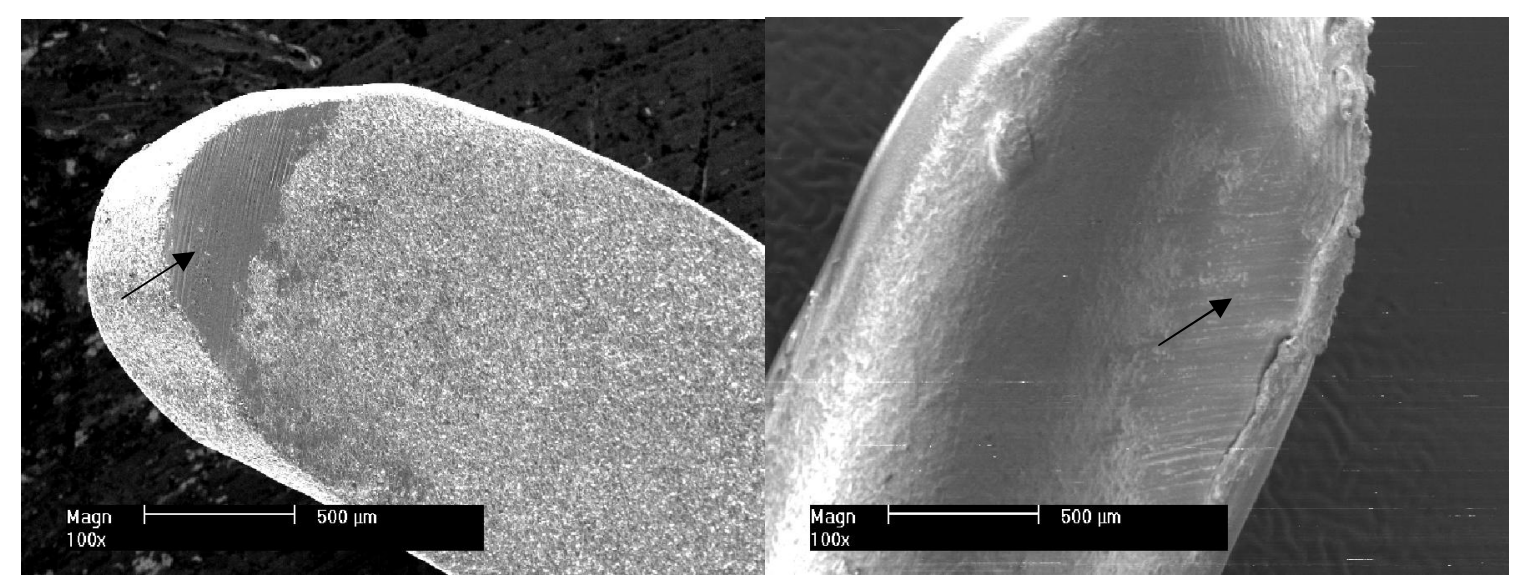

Fig. 13. SEM image of the inner surface of the clasp (left: CoCr clasp, right: resin clasp). Arrows indicate facets of wear. 


\section{Discussion}

\subsection{M aterials}

Materials for clasps and frameworks of partial removable dental prostheses (PRDPs) need to have enough flexibility for the clasps and rigidity for other framework components. Therefore, $\mathrm{CoCr}$ is the most popular alloy for the frameworks of PRDPs. The biggest disadvantage of $\mathrm{CoCr}$ clasps is their poor esthetic appearance. Tooth colored clasps made of thermoplastic resins have been developed to overcome the esthetic problems. In this study $\mathrm{CoCr}$ alloy served as the control group while three types of thermoplastic resins (POM, PEEK, PEKK) served as test groups.

\subsection{M ethods}

\subsubsection{A butments}

A maxillary first premolar has been used to make the abutments used in this study for two reasons, (1) esthetically: because the first premolar represents an esthetic problem when it must be used as retainers for an PRDP, (2) functionally: because cast $\mathrm{CoCr}$ alloy can be too stiff for occlusally approaching clasps on premolar teeth, and as a result more stress on the abutment could be produced [13].

The retentive force is dictated by tooth shape and by clasp design. Tooth shape influences retention by determining the depth of undercut available for clasping [12]. This study was designed to compare the retentive forces of clasps in two different amounts of undercuts. The $0.25 \mathrm{~mm}$ undercut was chosen because it represents the undercut commonly used for $\mathrm{CoCr}$ clasps, while the $0.50 \mathrm{~mm}$ undercut was selected to simulate the cases where clasps should be placed closer to the gingival margin, where undercut tends to be deeper, thereby producing a more esthetic result. 


\subsubsection{Circumferential clasp}

Although a thorough knowledge of the principles of clasp design should lead to a logical application of those principles, it is better that some of the more common clasp designs be considered individually. The circumferential clasp (Fig. 1) will be considered first as an allcast clasp [9].

The circumferential clasp is usually the most logical clasp to use with all tooth-supported partial dentures because of its retentive and stabilizing ability. Only when the retentive undercut may be approached better with a bar clasp arm or when esthetics will be enhanced should the latter be used (Fig. 1) [9].

Despite its disadvantages the cast circumferential clasp arm may be used effectively, and many of these disadvantages may be minimized by mouth preparation. Adequate mouth preparation will permit its point of origin to be placed far enough below the occlusal surface to avoid poor esthetics and increased tooth dimensions. Although some of the disadvantages listed imply that the bar-type clasp may be preferable, the circumferential clasp is actually superior to a bar clasp arm that is improperly used or poorly designed [9].

\subsubsection{Dimensions of the clasp}

If a clasp is too flexible, it will provide less retention for PRDP. The flexibility of a clasp is dependent on its section, length, thickness and material [12]. In the present study two thicknesses $(1.0 \mathrm{~mm}$ and $1.5 \mathrm{~mm})$ have been selected to make the thermoplastic resin clasps.

\subsubsection{Test conditions}

To perform the retention test, a masticatory simulator (Willytec, Munich, Germany) was used. The machine allows the placement of the clasp to its predetermined terminal position and its subsequent removal from the abutment crown, thus simulating the placement and removal of a PRDP. The models with the crowns were mounted in the masticatory simulator. Each clasp specimen was then placed on the corresponding abutment crown and fixed to the upper part of machine with auto-polymerizing acrylic resin (Technovit 4000, Heraeus-Kulzer). 
In previous similar studies [6, 27,33], simulating test has been performed on a masticatory simulator, and clasp retention has been measured every cycling sequence using another machine (tensile testing machine). To get the clasp on the two machines every time in the exact same position is very difficult, this could produce greater load on the abutments and lead to retention loss in a short time. In the current study, simulating test and retention measurement have been made using the same machine; this procedure has eliminated any mismatch in the clasp position.

In the present study, every clasp had its own tooth abutment, and this has reduced the possibility of abutment wear, so that the retentive force could be measured more accurately. While in previous studies [6, 33, 49], clasp retentive forces were measured and cyclic fatigue tests were performed on a single abutment tooth.

\subsection{Results}

Based on the data obtained in this investigation, the CoCr clasps showed significantly higher retention force as thermoplastic resin claps. Therefore, the null hypothesis that there would be no difference in the retentive force between resin clasps and cast $\mathrm{CoCr}$ alloy clasps was rejected.

Turner et al. examined the flexural properties of POM to determine the appropriate designs for the PRDP clasp. They suggested that a suitable POM clasp must be approximately $5 \mathrm{~mm}$ shorter with a larger cross-sectional diameter (approximately $1.4 \mathrm{~mm}$ ) in order to have the stiffness similar to a cast CoCr clasp $15 \mathrm{~mm}$ long and $1 \mathrm{~mm}$ in diameter[61]. Also, Fitton et al. stated that the POM clasps must have greater cross-section area than metal claps to provide adequate retention [20]. The results of the present study verify these findings, the greatest retentive force for POM clasps was found in the $1.5 \mathrm{~mm}$ thick clasps designed to engage the $0.50 \mathrm{~mm}$ undercut, the same was for PEKK and PEEK. Thermoplastic resin clasps should be thicker than metal clasps and engage a deeper undercut to gain clinically acceptable retention. This is due to the relatively low rigidity of the thermoplastic resin (elastic modulus; $2.36 \mathrm{GPa}$ for POM and 4.0 GPa for PEEK and PEKK as compared to $240 \mathrm{GPa}$ for $\mathrm{CoCr}$ alloy) [36, 61].

It could be claimed that the two bulkier designs which used to make the thermoplastic clasps could prevent the self-cleaning functions and cause more plaque accumulation. However, 
several studies showed that if plaque control is established and a regular recall system with control, re-instruction and re-motivation is provided, PRDPs might not cause damage to the periodontium [5, 43]. Shimura et al. found that the plaque formation on the buccal surface is not dependent on the type or placement of clasps, and suggested to prepare the guide plane as close to the gingival margin as possible to reduce the plaque accumulation on the distoproximal surface [55]. However, clinical studies are recommended to evaluate the effect of resin clasps on the plaque accumulation on the abutment teeth.

The results of the present study showed that resin clasps of both dimensions had significantly lower retentive force than $\mathrm{CoCr}$ clasps. Sato et al. suggested that a retentive force of $5 \mathrm{~N}$ is required for adequate function of PRDPs [52]. Frank et al. showed that 3 to $7.5 \mathrm{~N}$ represents an acceptable amount of retention for a bilateral distal-extension PRDP [22]. In the current study, the mean retentive force for the $1.0 \mathrm{~mm}$ thick thermoplastic resin clasps at the end of the cycling test ranged from $1.7 \mathrm{~N}$ to $3.7 \mathrm{~N}$, and for the $1.5 \mathrm{~mm}$ thick clasps from $5.4 \mathrm{~N}$ to $10.8 \mathrm{~N}$. These results reveal that thermoplastic resins could be used in the fabrication of clasps for PRDPs, as they provide adequate retention for PRDP even after 10 years of simulated usage.

Previous studies on the fatigue resistance of $\mathrm{CoCr}$ clasps have indicated a loss of retention because of permanent deformation of the metal $[25,33]$. The results of this study showed no significant difference between the initial and the final retention. This can be explained by the method which used to carry out the test. In the present study, the simulating test and the measurement of retentive forces have been performed using the same machine; the clasps have been fixed in the upper part of the testing machine using auto-polymerizing acrylic resin. These two procedures may reduce or eliminate all possibilities of torquing and ensured a straight path during cycling, and, thus, may have influenced the experimental outcome positively. Any excess torquing may affect the outcome of clasps negatively [6]. The increase of retention force observed in the first period of simulating could be explained by the wear between the crown and the inner surface of the clasp, which might have induced an increase in roughness of these two components during the first period of cycling, after that, the increased wear, caused a decrease in retention.

Limitations of this study include that the test was performed in a rigid system. The results under clinical conditions may not be the same due to the presence of periodontal ligament 
which allows physiological mobility of natural teeth. In the mouth, there are usually different insertion and removal paths, since obtaining truly effective guide planes is conditioned by anatomical aspects. Additionally, patients can change the path used to move the PRDP at each insertion and/ or removal cycle, producing greater loads on the tooth, thus leading to permanent clasp defects in a short period of time. These factors may have increased the retentive force values for the test compared to actual clinical usage. Therefore, further studies are needed, in conditions closer to clinical situations. 


\section{Conclusions}

Within the limitations of this study, the following conclusions were drawn:

1. The mean retentive force required to remove the $1.0 \mathrm{~mm}$ thick thermoplastic resin clasps was found to be significantly lower ( $\mathrm{P} \unlhd$ (0.001) than those required for removal of the of $1.5 \mathrm{~mm}$ thick clasps with $0.25 \mathrm{~mm}$ and $0.50 \mathrm{~mm}$ undercuts.

2. The mean retentive force required to remove the $1.0 \mathrm{~mm}$ and $1.5 \mathrm{~mm}$ thick thermoplastic resin clasps was found to be significantly lower (P $₫ 0.001$ ) than those required for removal of the CoCr clasps with $0.25 \mathrm{~mm}$ and $0.50 \mathrm{~mm}$ undercuts.

3. The retentive force required for $1.0 \mathrm{~mm}$ - and $1.5 \mathrm{~mm}$-thick thermoplastic resin clasps demonstrated no significant change over the simulating test of clinical usage. 


\section{Summary}

Statement of problem: Thermoplastic resin clasps have been used recently in the partial removable dental prostheses construction. However, little is known about the long-term retentiveness of these clasps under clinical conditions.

Objectives: The objective of this study was to evaluate the retentive force of clasps made from three thermoplastic resins and a cobalt-chromium alloy $(\mathrm{CoCr})$ alloy by the insertion/removal test simulating 10 years usage.

M ethods: On standardized premolar metal crowns 112 clasps were fabricated, including 16 $\mathrm{CoCr}$ (Wironit; $1.0 \mathrm{~mm}$ thick) clasps and 32 clasps (1.0 or $1.5 \mathrm{~mm}$ thick) from each of the following thermoplastic resins: Acetal-Dental, BioXS, PEKKtone A. Specimens were divided in subgroups with clasp undercuts of $0.25 \mathrm{~mm}$ and $0.5 \mathrm{~mm}$, respectively. Each clasp assembly was subjected to an insertion/removal test on its abutment crown for 15,000 cycles. To analyze the data obtained during the simulation test, intervals every 1,500 cycles were established. Data were statistically analyzed using 4-way and 2-way ANOVAs $(\alpha=0.05)$.

Results: Resin clasps with $1.5 \mathrm{~mm}$ thickness showed higher retention than clasps with 1.0 $\mathrm{mm}$ thickness (P $\$$ ).001). Resin clasps of both dimensions had significantly lower retentive force than CoCr clasps (P $₫ 0.001$ ). Clasps with $0.25 \mathrm{~mm}$ undercut showed significantly less retention than clasps with $0.50 \mathrm{~mm}(\mathrm{P} \unlhd \mathbf{} \mathbf{0} .001)$. All the clasps exhibited an increase in retentive force during the first period of cycling followed by continuous decrease till the end of the cycling but it was still significantly not different compared to the initial retentive force $(\mathrm{P}=0.970)$.

Conclusions: Thermoplastic resin clasps maintained retention over 15.000 joining and separating cycles with lower retention than conventional $\mathrm{CoCr}$ clasps. However, the retention of adequately designed resin clasps might be sufficient for clinical use.

Clinical I mplications: Thermoplastic resin clasps were determined to maintain clinically adequate retention over 10 years simulated use. Clinical studies are required to prove that thermoplastic resins are alternative for PRDP fabrication. 


\section{Zusammenfassung}

\section{Beschreibung des Problems:}

Klammern aus thermoplastischem Kunststoff werden seit neustem für die Konstruktion von Modellgussprothesen verwendet. Aber über die Retention dieser Klammern bei längerem klinischen Gebrauch ist wenig bekannt.

Ziele:

Das Ziel dieser Studie war es, den Halt von Klammern aus drei verschiedenen thermoplastischen Kunststoffen mit Klammern aus einer Kobalt-Chrom-Legierung zu vergleichen. Dafür wurde ein Einsetzungs-/Entfernungstest verwendet, der 10 Jahre klinischen Einsatz simuliert.

\section{M ethoden:}

Auf genormten Prämolar-Gusskronen wurden 112 Klammern hergestellt, davon 16 aus einer Kobalt-Chrom-Legierung (Wironit, 1,0 mm dick) und je 32 Klammern (1,0 oder 1,5 mm dick) aus den folgenden thermoplastischen Kunststoffen: Acetal-Dental, BioXS und PEKKtone A. Die Proben wurden unterteilt in Gruppen mit Unterschnitten zu 0,25 mm bzw. 0,5 mm. Jede Klammer wurde auf ihrer Krone einem Einsetzungs-/Entfernungstest mit 15.000 Zyklen unterzogen. Um die Daten aus dem Simulationstest zu analysieren, wurden Intervalle von je 1.500 Zyklen festgelegt. Die statistische Analyse der Daten erfolgte unter Zuhilfenahme von vier- und zweifaktoriellen Univarianzanalysen $(\alpha=0.05)$.

\section{Ergebnisse:}

Die Kunststoff-Klammern mit einer Dicke von 1,5 mm wiesen eine höhere Retention auf als Klammern mit einer Dicke von nur 1,0 mm (P \0.001). Kunststoff-Klammern beider Stärken zeigten signifikant schwächere Retention als die CoCr-Klammern (P \0.001). Zudem wiesen Klammern mit 0,25 mm Unterschnitt eine signifikant schwächere Retention auf als Klammern mit 0,5 mm Unterschnitt (P \0.001). Außerdem wiesen alle Klammern eine erhöhte Retention während des ersten Simulationsintervalls auf. Darauf folgte eine kontinuierliche Abnahme der Retention bis zum Ende der Simulation. Der Endwert der Retention war jedoch vom Anfangswert nicht statistisch signifikant verschieden $(\mathrm{P}>0,05)$. 
Schlussfolgerungen:

Die Klammern aus thermoplastischem Kunststoffen behielten ihre Retention über 15.000 Zyklen des Einsetzungs-/Entfernungstest bei, aber mit einer insgesamt geringeren Retention als die konventionellen CoCr-Klammern. Die Retention von entsprechend gestalteten Kunststoff-Klammern kann aber für den Einsatz am Patienten ausreichend sein. 


\section{References}

1. Arda T. and Arikan A. An in vitro comparison of retentive force and deformation of acetal resin and cobalt-chromium clasps. J Prosthet Dent 2005; 94:267-74.

2. Arikan A., Ozkan Y.K., Arda T., and Akalin B. An in vitro investigation of water sorption and solubility of two acetal denture base materials. Eur J Prosthodont Restor Dent 2005; 13:11922.

3. Asher M.L. Application of the rotational path design concept to a removable partial denture with a distal-extension base. J Prosthet Dent 1992; 68:641-3.

4. Baharav H., Ben-Ur Z., Laufer B.Z., and Cardash H.S. Removable partial denture with a lateral rotational path of insertion. Quintessence Int 1995; 26:531-3.

5. Bergman B., Hugoson A., and Olsson C.O. A 25 year longitudinal study of patients treated with removable partial dentures. J Oral Rehabil 1995; 22:595-9.

6. Bridgeman J.T., Marker V.A., Hummel S.K., Benson B.W., and Pace L.L. Comparison of titanium and cobalt-chromium removable partial denture clasps. J Prosthet Dent 1997; 78:18793.

7. Brudvik J.S. and Palacios R. Lingual retention and the elimination of the visible clasp arm. J Esthet Restor Dent 2007; 19:247-54; discussion 255.

8. Byron R., Jr., Frazer R.Q., and Herren M.C. Rotational path removable partial denture: an esthetic alternative. Gen Dent 2007; 55:245-50; quiz 251, 264.

9. Carr AB M.G., Brown DT. McCracken's removable partial prosthodontics. 11th edition2005: St. Louis: Elsevier. p. 79-115.

10. Chu C.H. and Chow T.W. Esthetic designs of removable partial dentures. Gen Dent 2003; $51: 322-4$.

11. Corrente G., Vergnano L., Pascetta R., and Ramadori G. A new custom-made abutment for dental implants: a technical note. Int J Oral Maxillofac Implants 1995; 10:604-8.

12. Davenport J.C., Basker R.M., Heath J.R., Ralph J.P., and Glantz P.O. Retention. Br Dent J 2000; 189:646-57.

13. David A. Mitchell L.M. Oxford Handbook of Clinical Dentistry 3rd ed. 2005, New York: Oxford University Press. p. 344.

14. Donovan T.E., Derbabian K., Kaneko L., and Wright R. Esthetic considerations in removable prosthodontics. J Esthet Restor Dent 2001; 13:241-53.

15. Douglass C.W. and Watson A.J. Future needs for fixed and removable partial dentures in the United States. J Prosthet Dent 2002; 87:9-14. 
16. Erich Wintermantel S.-W.H. Biokompatible Werkstoffe und Bauweisen. 2nd ed. 1998: Springer.

17. Eschbach L. Nonresorbable polymers in bone surgery. Injury 2000; 31 Suppl 4:22-7.

18. Faltermeier A., Behr M., and Mussig D. In vitro colour stability of aesthetic brackets. Eur J Orthod 2007; 29:354-8.

19. Firtell D.N. and Jacobson T.E. Removable partial dentures with rotational paths of insertion: problem analysis. J Prosthet Dent 1983; 50:8-15.

20. Fitton J.S., Davies E.H., Howlett J.A., and Pearson G.J. The physical properties of a polyacetal denture resin. Clin Mater 1994; 17:125-9.

21. Frank R.P. Direct retainers for distal-extension removable partial dentures. J Prosthet Dent 1986; 56:562-7.

22. Frank R.P. and Nicholls J.I. A study of the flexibility of wrought wire clasps. J Prosthet Dent 1981; 45:259-67.

23. Gapido C.G., Kobayashi H., Miyakawa O., and Kohno S. Fatigue resistance of cast occlusal rests using Co-Cr and Ag-Pd-Cu-Au alloys. J Prosthet Dent 2003; 90:261-9.

24. Garcia L.T. The use of a rotational-path design for a mandibular removable partial denture. Compend Contin Educ Dent 2004; 25:552-67.

25. Ghani F. and Mahood M. A laboratory examination of the behaviour of cast cobalt-chromium clasps. J Oral Rehabil 1990; 17:229-37.

26. Halberstam S.C. and Renner R.P. The rotational path removable partial denture: the overlooked alternative. Compendium 1993; 14:544, 546-52; Quiz 552.

27. Helal M.A., Baraka O.A., Sanad M.E., Ludwig K., and Kern M. Effects of long-term simulated RPD clasp attachment/detachment on retention loss and wear for two clasp types and three abutment material surfaces. J Prosthodont 2012; 21:370-7.

28. Jacobson T.E. Rotational path partial denture design: a 10-year clinical follow-up--Part I. J Prosthet Dent 1994; 71:271-7.

29. Jacobson T.E. Rotational path partial denture design: a 10-year clinical follow-up--Part II. J Prosthet Dent 1994; 71:278-82.

30. Jacobson T.E. and Krol A.J. Rotational path removable partial denture design. J Prosthet Dent 1982; 48:370-6.

31. Jones J.D. and García L.T. Removable partial dentures: a clinician's guide. 1st ed. 2009: Blackwell Publishing. p. 40. 
32. Keltjens H.M., Mulder J., Kayser A.F., and Creugers N.H. Fit of direct retainers in removable partial dentures after 8 years of use. J Oral Rehabil 1997; 24:138-42.

33. Kim D., Park C., Yi Y., and Cho L. Comparison of cast Ti-Ni alloy clasp retention with conventional removable partial denture clasps. J Prosthet Dent 2004; 91:374-82.

34. Kinsella K. Future longevity - demographic concerns and consequences. J Am Geriatr Soc 2005; 53:299-303.

35. Kotake M., Wakabayashi N., Ai M., Yoneyama T., and Hamanaka H. Fatigue resistance of titanium-nickel alloy cast clasps. Int J Prosthodont 1997; 10:547-52.

36. Kurtz S.M. and Devine J.N. PEEK biomaterials in trauma, orthopedic, and spinal implants. Biomaterials 2007; 28:4845-69.

37. Lowe L.G. Flexible denture flanges for patients exhibiting undercut tuberosities and reduced width of the buccal vestibule: a clinical report. J Prosthet Dent 2004; 92:128-31.

38. Luk K., Tsai T., Hsu S., and Wang F.L. Unilateral rotational path removable partial dentures for tilted mandibular molars: design and clinical applications. J Prosthet Dent 1997; 78:102-5.

39. Mahmoud A. Pre-overloading to extend fatigue life of cast clasps. J Dent Res 2007; 86:86872.

40. Mahmoud A., Wakabayashi N., Takahashi H., and Ohyama T. Deflection fatigue of Ti-6Al7Nb, Co-Cr, and gold alloy cast clasps. J Prosthet Dent 2005; 93:183-8.

41. Mahmoud A.A., Wakabayashi N., and Takahashi H. Prediction of permanent deformation in cast clasps for denture prostheses using a validated nonlinear finite element model. Dent Mater 2007; 23:317-24.

42. Martinez-Gonzalez A., Amigo-Borras V., Fons-Font A., Selva-Otaolaurruchi E., and LabaigRueda C. Response of three types of cast posts and cores to static loading. Quintessence Int 2001; 32:552-60.

43. Mine K., Fueki K., and Igarashi Y. Microbiological risk for periodontitis of abutment teeth in patients with removable partial dentures. J Oral Rehabil 2009; 36:696-702.

44. Moreno de Delgado M., Garcia L.T., and Rudd K.D. Camouflaging partial denture clasps. J Prosthet Dent 1986; 55:656-60.

45. Muller F., Naharro M., and Carlsson G.E. What are the prevalence and incidence of tooth loss in the adult and elderly population in Europe? Clin Oral Implants Res 2007; 18 Suppl 3:2-14.

46. Ozkan Y., Arikan A., Akalin B., and Arda T. A study to assess the colour stability of acetal resins subjected to thermocycling. Eur J Prosthodont Restor Dent 2005; 13:10-4. 
47. Pardo-Mindan S. and Ruiz-Villandiego J.C. A flexible lingual clasp as an esthetic alternative: a clinical report. J Prosthet Dent 1993; 69:245-6.

48. Phoenix R.D., Mansueto M.A., Ackerman N.A., and Jones R.E. Evaluation of mechanical and thermal properties of commonly used denture base resins. J Prosthodont 2004; 13:17-27.

49. Rodrigues R.C., Ribeiro R.F., de Mattos Mda G., and Bezzon O.L. Comparative study of circumferential clasp retention force for titanium and cobalt-chromium removable partial dentures. J Prosthet Dent 2002; 88:290-6.

50. Samet N. and Shohat M. [A systematic approach for removable partial denture design]. Refuat Hapeh Vehashinayim 2003; 20:71-6, 83.

51. Sato Y., Abe Y., Yuasa Y., and Akagawa Y. Effect of friction coefficient on Akers clasp retention. J Prosthet Dent 1997; 78:22-7.

52. Sato Y., Tsuga K., Abe Y., Asahara S., and Akagawa Y. Analysis of stiffness and stress in Ibar clasps. J Oral Rehabil 2001; 28:596-600.

53. Sato Y., Tsuga K., Abe Y., Asahara S., and Akagawa Y. Finite element analysis on preferable I-bar clasp shape. J Oral Rehabil 2001; 28:413-7.

54. Sato Y., Yuasa Y., Akagawa Y., and Ohkawa S. An investigation of preferable taper and thickness ratios for cast circumferential clasp arms using finite element analysis. Int $\mathbf{J}$ Prosthodont 1995; 8:392-7.

55. Shimura Y., Wadachi J., Nakamura T., Mizutani H., and Igarashi Y. Influence of removable partial dentures on the formation of dental plaque on abutment teeth. J Prosthodont Res 2010; 54:29-35.

56. Snyder H.A., Duncanson M.G., Jr., Johnson D.L., and Bloom J. Effects of clasp flexure on a 4-META adhered light-polymerized composite resin. Int J Prosthodont 1991; 4:364-70.

57. Suh J.S. and Billy E.J. Rotational path removable partial denture (RPD): conservative esthetic treatment option for the edentulous mandibular anterior region: a case report. J Esthet Restor Dent 2008; 20:98-105; discussion 106-7.

58. Sykes L.M., Dullabh H.D., and Sukha A.K. Use of technopolymer clasps in prostheses for patients due to have radiation therapy. Sadj 2002; 57:29-32.

59. Tetelman E.D. and Babbush C.A. A new transitional abutment for immediate aesthetics and function. Implant Dent 2008; 17:51-8.

60. Toth J.M., Wang M., Estes B.T., Scifert J.L., Seim H.B., 3rd, and Turner A.S. Polyetheretherketone as a biomaterial for spinal applications. Biomaterials 2006; 27:324-34.

61. Turner J.W., Radford D.R., and Sherriff M. Flexural properties and surface finishing of acetal resin denture clasps. J Prosthodont 1999; 8:188-95. 
62. Vallittu P.K. Fatigue resistance and stress of wrought-steel wire clasps. J Prosthodont 1996; $5: 186-92$.

63. Vallittu P.K. and Kokkonen M. Deflection fatigue of cobalt-chromium, titanium, and gold alloy cast denture clasp. J Prosthet Dent 1995; 74:412-9.

64. VandenBrink J.P., Wolfaardt J.F., and Faulkner M.G. A comparison of various removable partial denture clasp materials and fabrication procedure for placing clasps on canine and premolar teeth. J Prosthet Dent 1993; 70:180-8.

65. Wang R.R. and Fenton A. Titanium for prosthodontic applications: a review of the literature. Quintessence Int 1996; 27:401-8.

66. Yamaga T. and Nokubi T. Clasping system with rotational path of insertion Part 3. Clinical application. J Osaka Univ Dent Sch 1994; 34:57-63.

67. Yip K.H., Fang D.T., Smales R.J., Newsome P.R., and Chow T.W. Rotational path of insertion for removable partial dentures with an anterior saddle. Prim Dent Care 2003; 10:136.

68. Yuasa Y. Finite Element Analysis of the Relationship between Clasp Dimensions and Flexibility. J Dent R 1990.

69. Zitzmann N.U., Hagmann E., and Weiger R. What is the prevalence of various types of prosthetic dental restorations in Europe? Clin Oral Implants Res 2007; 18 Suppl 3:20-33. 


\section{CURRICULUM VITAE}

\section{PERSONAL DETAILS}

Name: $\quad$ Fahed Tannous

Address: $\quad$ Am Pferdemarkt 5

27356 Rotenburg

ftannous@proth.uni-kiel.de

Telephone: $\quad 004917647034760$

Date of birth: $\quad$ 20/06/1978

Place of birth: Hama, Syria

Marital status: $\quad$ Single

Nationality: Syrian

\section{ACADEMIC QUALIFICATIONS}

1996 - $2001 \quad$ Bachelor of Dentistry, Al Baath University, Syria

Average: $69,83 \%$

2001 - 2003 Diploma in Prosthodontics, Damascus University, Syria

Average: $73,09 \%$

2005 - 2006 Master’s degree in Prosthodontics, Damascus University,

Syria, Average: $90 \%$

09/11/2011 German equivalency dental examination 
WORK EXPERIENCE

$2003-2006$

$2002-2006$

$2007-2011$
Assistant in the Faculty of Dentistry, Al Baath

University, Syria

General Dentist in a private dental clinic, Syria

Visiting research fellow in the Department of Prosthodontics,

Propaedeutics and Dental Materials, Christian-Albrechts

University at Kiel, Germany

\section{PUBLICATIONS}

Tannous F., Steiner M., Shahin R., and Kern M. Retentive forces and fatigue resistance of thermoplastic resin clasps. Dent Mater 2012; 28:273-8. 


\section{Danksagung}

An dieser Stelle möchte ich mich bei allen Personen bedanken, die zum Gelingen dieser Arbeit beigetragen haben.

Mein besonderer Dank gilt Herrn Prof. Dr. Matthias Kern, der die Durchführung dieser Studie ermöglicht und mir viele hilfreiche Anregungen und wissenschaftliche Beratung gegeben hat.

Desweiteren möchte ich mich bei Dr. Martin Steiner und bei allen Mitarbeitern des wissenschaftlichen Labors in der Klinik für zahnärztliche Prothetik, Propädeutik und Werkstoffkunde für die hilfreiche Unterstützung bedanken. 